\title{
Feed-in tariffs for promotion of energy storage technologies
}

Article in Energy Policy · March 2011

Impact Factor: $2.58 \cdot$ DOI: 10.1016/j.enpol.2010.12.013 · Source: RePEc

CITATIONS

25

7 authors, including:

Goran Krajacic

University of Zagreb

67 PUBLICATIONS 446 CITATIONS

SEE PROFILE

\section{Antonis G. Tsikalakis}

National Technical University of Athens

38 PUBLICATIONS 824 CITATIONS

SEE PROFILE
Neven Duic

University of Zagreb

406 PUBLICATIONS $\quad 1,569$ CITATIONS

SEE PROFILE

MGS Carvalho

European Commission

170 PUBLICATIONS $\quad 2,729$ CITATIONS

SEE PROFILE 


\title{
Feed-in tariffs for promotion of energy storage technologies
}

\author{
Goran Krajačić ${ }^{\mathrm{a}, *}$, Neven Duić ${ }^{\mathrm{a}, \mathrm{b}}$, Antonis Tsikalakis $^{\mathrm{c}}$, Manos Zoulias ${ }^{\mathrm{d}}$, George Caralis ${ }^{c}$, Eirini Panteri ${ }^{\mathrm{e}}$, \\ Maria da Graça Carvalho ${ }^{\text {b, } 1}$ \\ ${ }^{a}$ University of Zagreb, Faculty of Mechanical Engineering and Naval Architecture, Ivana Lučića 5, 10002 Zagreb, Croatia \\ ${ }^{\mathrm{b}}$ Instituto Superior Técnico, Lisbon, Portugal \\ ${ }^{\mathrm{c}}$ National Technical University of Athens, Athens, Greece \\ ${ }^{\mathrm{d}}$ Centre for Renewable Energy Sources \& Savings (CRES), Pikermi, Greece \\ e Regulatory Authority for Energy (RAE), Athens, Greece
}

\section{A R T I C L E I N F O}

Article history:

Received 28 April 2010

Accepted 7 December 2010

Available online 20 January 2011

Keywords:

Feed-in tariffs

Energy storage

Renewable energy sources

\begin{abstract}
A B S T R A C T
Faster market integration of new energy technologies can be achieved by use of proper support mechanisms that will create favourable market conditions for such technologies. The best examples of support mechanisms presented in the last two decades have been the various schemes for the promotion of renewable energy sources (RES). In the EU, the most successful supporting schemes are feed-in tariffs which have significantly increased utilisation of renewable energy sources in Germany, Spain, Portugal, Denmark and many other EU countries. Despite the successful feed-in tariffs for RES promotion, in many cases RES penetration is limited by power system requirements linked to the intermittency of RES sources and technical capabilities of grids. These problems can be solved by implementation of energy storage technologies like reversible or pumped hydro, hydrogen, batteries or any other technology that can be used for balancing or dump load. In this paper, feed-in tariffs for various energy storage technologies are discussed along with a proposal for their application in more appropriate regions. After successful application on islands and outermost regions, energy storage tariffs should be also applied in mainland power systems. Increased use of energy storage could optimise existing assets on the market.
\end{abstract}

(c) 2010 Elsevier Ltd. All rights reserved.

\section{Introduction}

In 2007, the EU decided on a set of compulsory renewable energy targets for 2020: an overall 20\% target (European Commission, 2005, 2008). However, the intermittent nature of renewable energy sources (RES) like wind, solar and waves is one of the limiting factors for their penetration in power systems, especially autonomous systems. Apart from progress in forecasting techniques (Giebel et al., 2003) or providing information to end-users regarding management of uncertainty (Tsikalakis et al., 2009a), energy storage applications can provide substantial help in managing intermittency (Barton and Infield, 2004). Energy storage is also set as one of four pillars of the EU Post Carbon Society (Carvalho et al., 2009). Efficiently designed financial schemes for storage systems may contribute to EU energy policy 20-20-20.

The available options for energy storage and integration of different energy and resources flows that could help solve intermittency

\footnotetext{
* Corresponding author. Tel.: +385 915658884; fax: +385 16156940 .

E-mail addresses: Goran.Krajacic@fsb.hr (G. Krajačić),

Neven.Duic@fsb.hr (N. Duić), atsikal@corfu.power.ece.ntua.gr (A. Tsikalakis), mzoulias@cres.gr (M. Zoulias), gcaralis@central.ntua.gr (G. Caralis), panteri@rae.gr (E. Panteri),

mariadagraca.carvalho@europarl.europa.eu (M.G. Carvalho).

${ }^{1}$ Presently Member of the European Parliament.
}

problems in the islands energy systems have been proposed using the Renewislands methodology (Duić et al., 2008). Case studies and calculations for pumped hydro and hydrogen have in many cases been proposed (Duić and Carvalho, 2004; Caralis and Zervos, 2006; Krajačić et al., 2008; Bueno and Carta, 2006; Kapsali and Kaldellis, 2010) or have been recently implemented, like in Madeira (Empresa de Electricidade da Madeira (EEM), 2010) or are under final construction, like on Ikaria Island in Greece (Public Power Corporation (PPC), 2010).

Efficient management of batteries in small island power systems with increased RES penetration can provide (in terms of adequacy in case of disturbance) both economic and operational benefits for the power systems operators as shown in Tsikalakis et al. (2004) for the island of Kythnos. Similarly, storage systems for islands based on the size of their energy systems have been proposed (Kaldellis et al., 2009), suggesting that storage could even contribute to a cost reduction in electricity production in such power systems.

Hydrogen has also been proposed as a storage means (Lund et al., 2007; Zoulias and Lymberopoulos, 2007; Parissis et al., 2009a, b). Electrolytic $\mathrm{H}_{2}$ production could be used as a load management method for wind power in weak distribution grids as explained in Korpas and Greiner (2008). $\mathrm{H}_{2}$ production and storage may become a viable option in areas where reinforcements of existing grids are costly or controversial due to environmental concerns. A similar conclusion is the advantage of the wind-hydrogen system over 
wind-only systems due to the fact that energy generation is manageable, hence bringing it closer to demand, as argued by Agustin and Lopez (2008).

As RES penetration increases in autonomous or weakly interconnected islands, operators issue instructions for temporarily disconnecting part of RES production. Similar problems will be faced by large power systems as RES penetration reaches certain levels. This excess electricity can be either exploited via heat pumps and thermal energy storage intended for harsh winter climate areas (Lund, 2005) or via ice banks or other cold energy storage systems in regions with cooling needs.

For islands where water scarcity is a reality, desalination can be considered as an alternative solution (Calero and Carta, 2004; Karagiannis and Soldatos, 2010; Psychogiopoulos et al., 2008; Kaldellis and Kondili, 2007). Subsequently, there are also places where desalination could effectively be applied in combination with renewable energy sources and pumped hydro storage systems (Segurado et al., 2011; Akash et al., 1997). Storage systems used in transport systems could also help RES integration (Lund and Kempton, 2008).

As the EU strives to reach goals in its energy policy, energy storage could make a great contribution if similar successful mechanisms were to be used for promoting RES. The Feed-in tariff (FIT) for storage and desalination technologies could be also applied in other parts of the World in order to attract investors to interesting solutions.

After a short description on design and application of FITs in various aspects of renewable energy sources and a description of their benefits, a design methodology of FITs for three types of energy storage methods and one Demand Side Management (DSM) method desalination are provided. Emphasis is given on Pump hydro storage technology, a mature storage technology, battery storage as well as desalination systems. Finally, some conclusions are made on the value of the proposed methodology.

\section{Feed-in tariffs application and design}

One of the issues for storage systems is that they increase the already high cost of distributed and renewable energy sources, making them mostly in market terms, even less economically viable. For the case of hydrogen, the additional price has been estimated within the range of 43-171 $\mathrm{c} € / \mathrm{kWh}$, as shown in Agustin and Lopez (2008) and Krajačić et al. (2009). However, some exceptions for battery systems (Tsikalakis et al., 2004) and hydrogen for the island of Corvo (Parissis et al., 2009a, b) suggest that under circumstances, storage can be a viable option.

However, it should not be overlooked that energy storage may provide even more benefits for power systems, which are difficult to be fully evaluated and accordingly remunerated (Wals and Hendriks, 2004). Indicatively, energy storage can help in local integration of solar energy (Kelsey, 2006), avoiding local upgrades of the distribution system (Rau and Tayor, 1998) or even contribute to facing power quality issues (Swaminathan and Sen, 1998).

To overcome financial barriers and create favourable market conditions for energy storage technologies, support schemes and policies must be developed. Feed-in tariffs, Green Certificates, tendering procedures, tax initiatives, and investment initiatives are examples of schemes that have been accepted by different governments and energy regulatory bodies.

As explained by Meyer (2003), due to the relatively high costs of production, wind power and other renewable sources of electricity, cannot in a free commercial market compete against mature technologies such as large hydro, combined cycle plants based on natural gas, efficient coal-fired combined heat and power plants or nuclear power plants. Therefore, special support systems are needed for RES until such technologies become commercially competitive. Recent experience from around the world suggests that feed-in tariffs are the most effective policy in encouraging rapid and sustained deployment of renewable energy (Couture and Gagnon, 2010). Also, as explained by Gonzalez (2008), FIT has made Spain and Germany two of the most successful countries in the public promotion of electricity from RES. FIT has led to the emergence of a RES technoinstitutional complex made up of learning networks between RES producers, RES equipment suppliers, local communities, policymakers and NGOs (Gonzalez and Gual, 2007).

Currently, only Greece among EU countries has regulatory framework that supports installation of hybrid systems including energy storage and RES (Hellenic Republic; Ministry of Development, 2006). Even though this framework is at some details revised, the main characteristics is that one tariff is set for electricity from an intermittent RES source, which is directly fed to the grid, while another is set for electricity produced by storage units. The amount of energy from the grid that can be used for storing energy is restricted and is used when RES is not easy to provide the firm power required by the island power system. The remuneration varies from island to island depending also on the marginal value of the price in each power system. Solano-Peralta et al. (2009) proposed FIT systems for the hybrid systems in Ecuador. The use of thermal energy storage in Denmark was indirectly supported through a triple tariff system used for CHP generation since excess capacities in CHP units can be used to relocate hours of electricity production if thermal energy storage is added to the CHP plant (Lund and Andersen, 2005).

There are several different ways to structure a FIT policy, each containing its own strengths and weaknesses. Couture and Gagnon (2010) presented an overview of seven different ways to structure the remuneration of a FIT policy. In general, they divided FIT into two broad categories: those in which remuneration is dependent on the electricity market price, and those that remain independent of it. In the same paper, the advantages and disadvantages of different FIT models were examined, and an analysis of design options was made focusing on the implications for both investors and society. Haas et al. (2004) and Gonzalez (2008) conclude that the specific design elements of support schemes and not so much the type of chosen support scheme are a major factor for their success. Political commitment and other factors including the granting of administrative authorisations are also important as they may cause delays in investments and render RES investments unattractive. This means that beside financial, there are many other barriers for RES installations identified by Oikonomou et al. (2009) and Suarez et al. (2009). In their work they also propose methodologies for overcoming identified barriers for RES installations. As presented by Garcia and Menendez (2006), utilities have been accused in the past of using third-party grid access as an obstacle to RES deployment. Such barriers should be addressed before implementing a FIT application for energy storage development. Alleviation of such barriers has been reported as issues of similar importance as the FIT itself (Lüthi, 2010).

By providing different support levels for various types of technologies, FIT are more likely to promote different types of technologies than say other instruments, which prioritise the cheapest technologies (Gonzalez and Gual, 2007). This is an important characteristic for FIT as there are many storage options on the market in various development stages.

A stepped FIT is characterised by lower tariff for technologies, locations and plant sizes possessing a greater efficiency (Gonzalez, 2008). Stepped FIT is a tool in reducing produced surplus and, consequently, the societal burden (Huber et al., 2004). Reducing support as the initial investment provides a return that can also be justified in order to reduce a windfall in profits for investors. In contrast, support was not adjusted according to the RES potentials of different locations, which is another positive element of a stepped FIT (Ragwitz et al., 2007). Reductions in support levels for new plants are linked to cost reductions due to economies of scale and learning effects (Gonzalez, 2008). Similar reduction of over profit for producers due to FIT 
application could lead to de-escalation of FIT over time. The deescalating of the feed-in tariff alleviates the burden on consumers who have to provide the funds for the subsidy through a specially designed RES tax. However, if technological progress envisaged in the policy design is not as quick as expected, the penetration of RES might abruptly cease when the feed-in tariffs fall below the technology's levelised cost (Danchev et al., 2010).

Lesser and Su (2008) explains the main difficulty with the development of FIT compared to other schemes. FIT requires policymakers to define administratively FIT attributes, specifically payments amounts for individual technologies (e.g., wind, solar, and geothermal), payment structures (e.g., fixed or declining), and payment durations. All three attributes can require significant 'guesswork' on the part of policymakers regarding future market conditions and the pace of technological improvements. On the other hand, Lipp (2007) concludes that the advantage of the FIT is that it differentiates various renewable energy technologies, at different stages of development that have different generation costs. Moreover, the FIT do not narrow competition, because in the interest of keeping construction costs low, developers try to buy the cheapest and best technologies and have thus driven the cost of technology down (Lipp, 2007). It could then be concluded that FIT for storage technologies (hydrogen and batteries) will help such technologies to "move up" on learning curves. As presented by Lipp (2007), in some countries FIT has a long history and an adequate administration to handle its procedures. In these countries, the use of FITs in storage systems could easily be accepted and would not affect the market greatly.

Lipp (2007) explains specific benefits that countries plan to gain using a FIT application. Most countries support the development of RES for the following reasons:

- Ensuring security of supply (reducing dependence on fossil fuels and creating diversity of supply).

- Reducing greenhouse gas emissions (and other environmental effects of the energy sector).

- Fostering innovation and broadening industrial capabilities (e.g. to improve export potential, skills and enhance competitiveness).

- Increasing local and regional benefits (e.g. through job creation, manufacturing, and economic development).

It is desirable to meet these objectives in the most cost-effective manner and this therefore is main reason for conducting a detailed

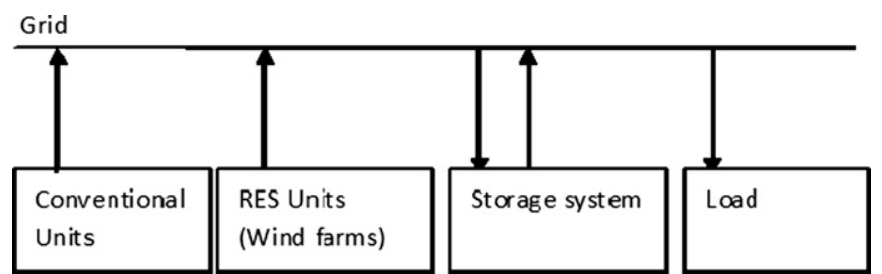

Fig. 1. Storage system as a separate unit. cost-benefit analysis before the application of storage systems (Parissis et al., 2009a, b).

As shown by Saenz de Miera et al. (2008), extensive public support for electricity from renewable energy sources (RES-E), in addition to environmental and socio-economic benefits, has also resulted in RES-E decreasing the total price of electricity. The additional amount of RESE, supported by the German RES-E policy (EEG), has reduced the wholesale price of electricity in 2005-2007 by $6.4 € / \mathrm{MWh}$ (Rathmann, 2007), while increasing the RES-E fee by $3.8 € / M W h$. Thus, Saenz de Miera et al. (2008) concludes that without the RES-E support, the retail price of electricity would have been $2.6 € / \mathrm{MWh}$ higher than it actually has been. Economic benefits have been reported in the operation of the Cretan power system (Tsikalakis et al., 2003) due to the FIT scheme for wind turbines.

The design of FIT for application in storage system is rather simple and could be easily performed by Energy Regulatory Agencies or Electricity Market Operators and assisted by experts from Transmission System Operator (TSO) and Distribution System Operator (DSO). The calculations necessary for evaluating a FIT design could be carried out by using energy planning models as described (Lund et al., 2007; Connolly et al., 2010).

\section{Feed-in tariffs for energy storage}

In general, two basic installations of storage systems exist, i.e. storage installed as separate unit (cf. Fig. 1) or as part of a hybrid system (cf. Fig. 2). The installation in a hybrid system does not necessary mean that producing RES units (wind or photovoltaic or any other power plant) are physically installed at the same location as the storage unit. It could be just a conceptual combination of these two plants where each unit has its own grid connection but are operated as a single hybrid system.

Each of the presented concepts has its own advantages and field of application. The storage systems as separate units are mostly used in big power systems with numerous production units, hence the size of storage units is larger. The most representative installations currently operating worldwide are large pumped hydropower plants. Hybrid systems are more common on the islands and in stand-alone applications.

\subsection{Feed-in tariffs for pumped hydro storage-PHS}

Pumped or reversible hydropower stations (PHS), not installed as hybrid systems, use energy from the grid to raise water to an upper reservoir. This energy may come from all the power plants in the system. In order to avoid taking power from conventional stations used for pumping and thus increasing emissions of pollutants, these kinds of PHS units should be supported only in systems with an established certification of the renewable origin of electricity ("guarantees of origin")-(GO). As mentioned in the introduction, FIT should be different with respect to project size, application, location or

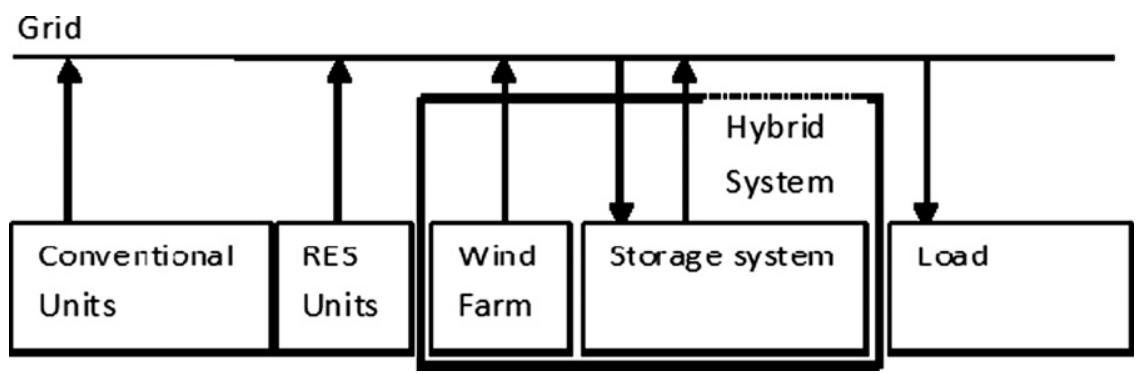

Fig. 2. Storage system as a part of a hybrid system. 
resource intensity and the same factors should be applied in supporting of PHS.

$F I T_{P H S_{W G O}}$ represents FIT, paid for electricity produced by PHS which is equal to electricity used for pumping decreased by the total efficiency of the PHS system. This means theoretically that electricity produced by PHS could also get amount of guarantees of origin for RES-E, only decreased by the PHS system efficiency. This is illustrated by the equation below

$P H S_{G O}=\eta_{P H S} W_{G O}$

where $P H S_{G O}$ are the guarantees of origin assigned to electricity produced by PHS and $W_{G O}$ are the guarantees of origin for wind electricity supplied from the network. $\eta_{P H S}$ is the total efficiency of PHS calculated by

$\eta_{P H S}=\eta_{T} \eta_{p}$

where $\eta_{T}$ is the turbine and generator efficiency and $\eta_{p}$ is the pumping efficiency. $\eta_{P H S}$ is an important factor and must be determined from technical documentation for proposed PHS or from data for typical groups of PHS.

If $\eta_{P H S}$ is $70 \%$ and if guarantees of origin are standardised at $1 \mathrm{MWh}$, then for $1 \mathrm{MWh}$ of $E_{P H S_{W G O}}$ (RES-E coming from PHS with provable renewable origin of electricity) or $1 \mathrm{PHS}_{\mathrm{GO}}$ will need to supply $1.4285 \mathrm{MWh}$ of $E_{W G O}$ (RES-E coming from wind power plants with provable renewable origin of electricity) or $1.4285 W_{G O}$. Complex accounting of GO requires a central registry which should be located at the energy market system operator and supported by power system operators (TSOs or DSOs). The importance of the given GO is explained by Ragwitz et al. (2009) who states that most probably, EU-wide trading of RES-E is likely to take the form of an exchange in guarantees of origin. Although there is obvious support for storage technology in the novel EU energy policy, according to the new RES directive (The European Parliament and the Council of the European Union, 2009), the production of electricity in pumped storage units from water previously pumped uphill is not treated as a renewable electricity. Consequently, it cannot receive guaranties of origin that are recognised at an EU level nor accepted by the European Commission. The aim here is to avoid twofold counting of produced renewable electricity.

In the scenario that PHS uses only electricity with $W_{G O}$ for pumping, and the turbine has a load factor $\leq 20 \%$, FIT should cover total costs of electricity production which will be paid for the electricity possessing $P H S_{G O}$ and is calculated by formula

$F I T_{P H S_{W G O}}=\left(\left(\frac{T I C_{P H S} R+O M C_{P H S}}{E_{P H S_{W G O}}}\right)_{W G O}+\left(\frac{E P C_{W G O}}{\eta_{P H S}}\right)_{W G O}\right)_{E_{P H S} S_{W G O}}$

where $T_{I C} C_{P H S}$ is the total investment cost in PHS, $O M C_{P H S}$ is yearly PHS operation and maintenance costs, $E_{P H S_{W G O}}$ is the total delivered electricity to the network by PHS. $E P C_{W G O}$ represents the market price of RES-E used in pumping. WGO indexes only indicate to which renewable origin of electricity the terms in brackets are related.

The annuity factor $R$ is defined as

$R=\frac{i}{1-(1+i)^{-N}}$

where $i$ is the discount rate and $N$ is the payback period of the investment.

The size of Hydropower Plants and Pumped Hydro Storage plants varies from a few hundred $\mathrm{kW}$ to hundreds of MW, leading consequently to a big span in installation costs. Another characteristic of PHS is that it could be built by adapting existing structures (adding a pump station and pumping penstock to existing hydropower plants which already have both reservoirs or by adding upper or lower reservoir, penstock, reversible turbines or turbines and pumps to existing water reservoir as described in the case studies of STORIES project Deliverable 2.1. (Tsikalakis et al., 2009b)).
Table 1

Overview of the formulas and assumptions for the PHS and WHPS cost estimation.

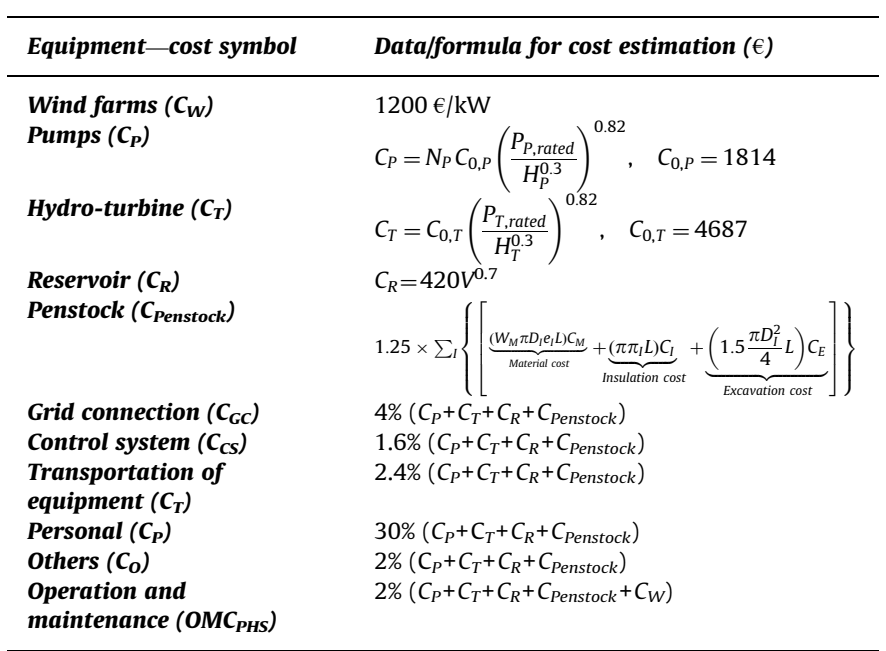

In the same deliverable, total costs of Hybrid Wind Pumped Hydro Storage WHPS and PHS are given by the formulas showed in Table 1. New developments of PHS and the respective installation costs and details are described by Caralis et al. (2010), Kapsali and Kaldellis (2010) and Deane et al. (2010).

FIT suggestions for PHS systems should take into account the local particularities of possibly developing PHS and accordingly, suggestions should propose one or several levels of FIT $_{P H S}$. For a specific energy system, the limit on turbine load factor in PHS, supported by a different level of FIT, can be optimised. This can be carried out according to desirable levels of excess production from RES units or according to the needs of supply security or energy autonomy of the system as described by Kaldellis et al. (2009), or wind capacity index and the reservoir's capacity index as used by Caralis et al. (2010). Kapsali and Kaldellis (2010) proposed the optimum sizing of a PHS system based on the maximisation of the net present value while (Bueno and Carta, 2006) used an optimum sized economic model to find solution for PHS system of the island Gran Canaria (Canarian Archipelago).

If the PHS system turbines have a capacity factor greater than $20 \%$, meaning they operate in excess of 1750 full load hours, the PHS system should then receive one FIT until it fulfills the quota of 1750 full load hours (or energy equivalent). FIT covering this production will allow PHS owners to make a return on investment at a set discount rate and within an expected time period. Another tariff between 1750 and 2750 full load hours is directly linked to the price of electricity used for pumping. Its purpose is to stimulate additional use of PHS in storing excess intermittent energy and thus reduce curtailment. The third tariff allows minimal earnings in storing excess and is set when PHS operates in excess of 2750 hours. In systems with one penstock, similar pump and turbines power, and no extra inflow of water in the upper reservoir, it can hardly be expected that turbines will operate in excess of 2750 full load hours. However, operation hours will be directly linked to system design and to the operational purpose of the PHS system.

Table 2 presents just one example of calculating stepped FIT and as mentioned before, and these limits will most probably be case related. Here, stepped tariff is calculated from investor's point of view while another approach for calculating stepped FIT could be trough the system optimisation. Therefore, the recommendation is to calculate stepped tariff for the group of similar case studies through system optimisation of the following parameters: security of energy supply or energy autonomy, reduction of RES-E excess rejection, desirable RES-E targets/penetration levels, system regulation, costs and benefits of PHS installation. Wind potential and 
Table 2

Possible structuring of FIT according to the turbine capacity factor

\begin{tabular}{ll}
\hline $\begin{array}{l}\text { Working hours at full load } \\
\text { (or energy equivalent) }\end{array}$ & FIT \\
\hline$<1750$ & $F I T_{P H S_{W G O}}$ \\
$1750-2750$ & $1.055 \times \frac{E P C_{W G O}}{\eta_{P H S}} \quad$ (5) \\
$>2750$ & $1.005 \times \frac{E P C_{W G O}}{\eta_{P H S}} \quad$ (6) \\
\hline
\end{tabular}

hydraulic head are site-dependent features, which strongly affect the attractiveness and profitability of the investment, but do not affect the hybrid wind and PHS energy contribution. In achieving a desirable hybrid wind and PHS energy contribution or a peak demand supply for a turbine, a specific wind energy amount combined with a specific storage capacity are required (Caralis et al., 2010).

When contracted, $F I T_{P H S_{W G O}}$ should last for some period. A period of 12 years seems reasonable from an investor's point of view and contracting should cover a 5 year period after FIT is inured (this provide some security to investors and system planners). Following this 5 year period, a revision of FIT is recommended.

Including $100 \%$ of the tariffs for protection against inflation is best way to ensure stability for investors. The amount of the FIT for electricity produced in plants using renewable energy sources during the validity of the electricity purchase contract is adjusted annually with respect to the retail price index. This is carried out by taking the FIT from the previous calendar year and multiplying it with the annual retail price index from the previous calendar year, i.e.

$F I T_{Y P H S}=$ FIT $_{\text {YPHS }-1} I R P_{Y P H S}-1$

where $F I T_{Y P H S}$ is the incentive price for the current calendar year. FIT $T_{\mathrm{YPHS}-1}$ is the incentive price from the previous calendar year. For the first year, it represents the amount of the tariff item $F I T_{Y P H S}$, prescribed by the tariff system. IRP $P_{Y P H S-1}$ is the annual retail price index according to official data from the Central Bureau of Statistics for the previous calendar year. YPHS is the yearly index.

Danchev et al. (2010) describes a system where the feed-in tariff schedule is updated each year, while taking into consideration the inflation rate. However, the compensation is not complete, but amounts only to $25 \%$ of inflation. The reason being is that anything less than full compensation provides incentives for constantly improving the efficiency of the subsidised unit through innovation, learning, and so on.

Another criticism against the FIT has been that favourable tariffs have typically not been reduced in step with technological development (Meyer, 2003). A supplementary solution would be to adjust the tariff for new installations at regular intervals taking into account the best technology on the market (bench marking principle).

When additional inflow of water in the upper reservoir exists, enabling load factor of turbines $\geq 20 \%$ (or higher of any other calculated desirable limit), FIT for electricity produced in this way is calculated according to Eq. (8)

FIT $_{P H S_{T G O}}=\left(\left(\frac{T I C_{T P S} R+O M C_{T P S}}{E_{P H S_{T G O}}}\right)_{T G O}\right)_{E_{P H S}-E_{P H S}{ }_{W G O}-E_{P H S} N O G O}$

$E_{P H S_{T G O}}=E_{P H S}-E_{P H S_{W G O}}-E_{P H S_{N O G O}}$

$E_{P H S_{W G O}}=\eta_{P H S} E_{W G O}$

$E_{P H S_{N O G O}}=\eta_{P H S} E_{N O G O}$

where $E_{P H S_{T C O}}$ is the electricity produced by turbinating extra inflow of water, $E_{P H S_{W G O}}$ is the electricity produced by PHS with GO (by $E_{W G O}$ - energy taken from the grid with $W_{G O}$ is used for pumping) and $E_{P H S_{\text {NOCO }}}$ is the electricity produced by PHS without GO (by $E_{N O G O}$ - energy taken from the grid without $W_{G O}$ is used for pumping). $T I C_{T P S}$ represents the total investment costs for a hydropower plant (turbines, generators, penstock and eventually upper reservoir without pumping part). The $F I T_{P H S_{T C O}}$ should only cover the cost of PHS when operating as a hydropower plant using extra inflow of water which means that $T_{I C} C_{T P S}$ should be determined from the ratio $E_{P H S_{T C O}} / E_{P H S}$. Extra inflow of water in the upper reservoirs could be easily determined as pumped volume will be always known. FIT for electricity produced from PHS if there are no guarantees of origin for electricity used for pumping, is calculated using

FIT $_{P H S_{\text {NOGO }}}=0$

meaning that the operator of PHS is buying electricity and selling back $E_{P H S_{N O G O}}$ at market price. This mode of PHS work should be allowed only if there are no scheduled requests for pumping of RES-E from the system operator in order to avoid curtailment.

If TSO or DSO due to some reason request the PHS operator to pump and fill upper storage, and if they cannot provide GO, the PHS owner should receive compensation for carrying out this operation (usually done in accordance with rules for balancing energy and is prescribed in network operation codes).

A proposal for organising the market in terms of invoicing, payments, insuring GO and fees for FIT is showed in Fig. 3. In organising such systems, it will be desirable to have Wind Power Dispatch Centres supporting DSO and TSO (Estanqueiro et al., 2008). This would enable undertaking a precise decision on what amount of electricity would be sourced from wind power plants and fed directly to system, and what would be used for pumping. This is important if GO is also to be determined for the PHS system, meaning the RES privileged producer will only get the amount of GO for its electricity directly absorbed by the system while part of the GO will be passed to PHS, decreased by its efficiency. In this way, twofold counting of produced RES-E is avoided and it is then possible to track RES-E, thus organising payments according FIT. Market operators at the end of each month or any other agreed payment period could easily calculate what amount of money, according to prescribed FIT, should be given to RES and PHS producers. As is also shown in Fig. 3, it is then possible to show final consumers the amount of GO and RES consumed therefore validating their payments.

\subsection{Feed-in tariffs for hybrid wind pumped hydro storage-WHPS}

If the market operator cannot ensure GO of origin for electricity taken and delivered from storage units, then it is possible to set up FIT tariffs according to Greek law (Hellenic Republic; Ministry of Development, 2006).

In order to cover costs of electricity production (EPC), the following condition must be always applied

FIT $_{T} \geq E P C_{T}$

The contribution of the WHPS, together with economical and reliability indexes, are used to describe the performance of the power system after WHPS integration. The conventional units' EPC $E P C_{C}$, the electrical system's EPC EPC $C_{S}$ and the turbine's EPC EPC $C_{T}$ are used to describe the economic impact of the WHPS on the electrical system. The most critical is the EPCS, when compared with the current cost, the resulting benefit - if any - from the WHPS integration is defined. The $E P C_{T}$ is important for the private investor, indicating a first estimation of the required price for the turbine's electricity production, and providing the feasibility benchmark for the investment. Finally, the modification of the $E P C_{C}$ on account of WHPS integration is critical for the $\mathrm{ESO}^{2}$ in order to accept this price.

\footnotetext{
${ }^{2}$ The autonomous islands are excluded from the market liberalisation and the system operator remains the owner of the local power stations.
} 


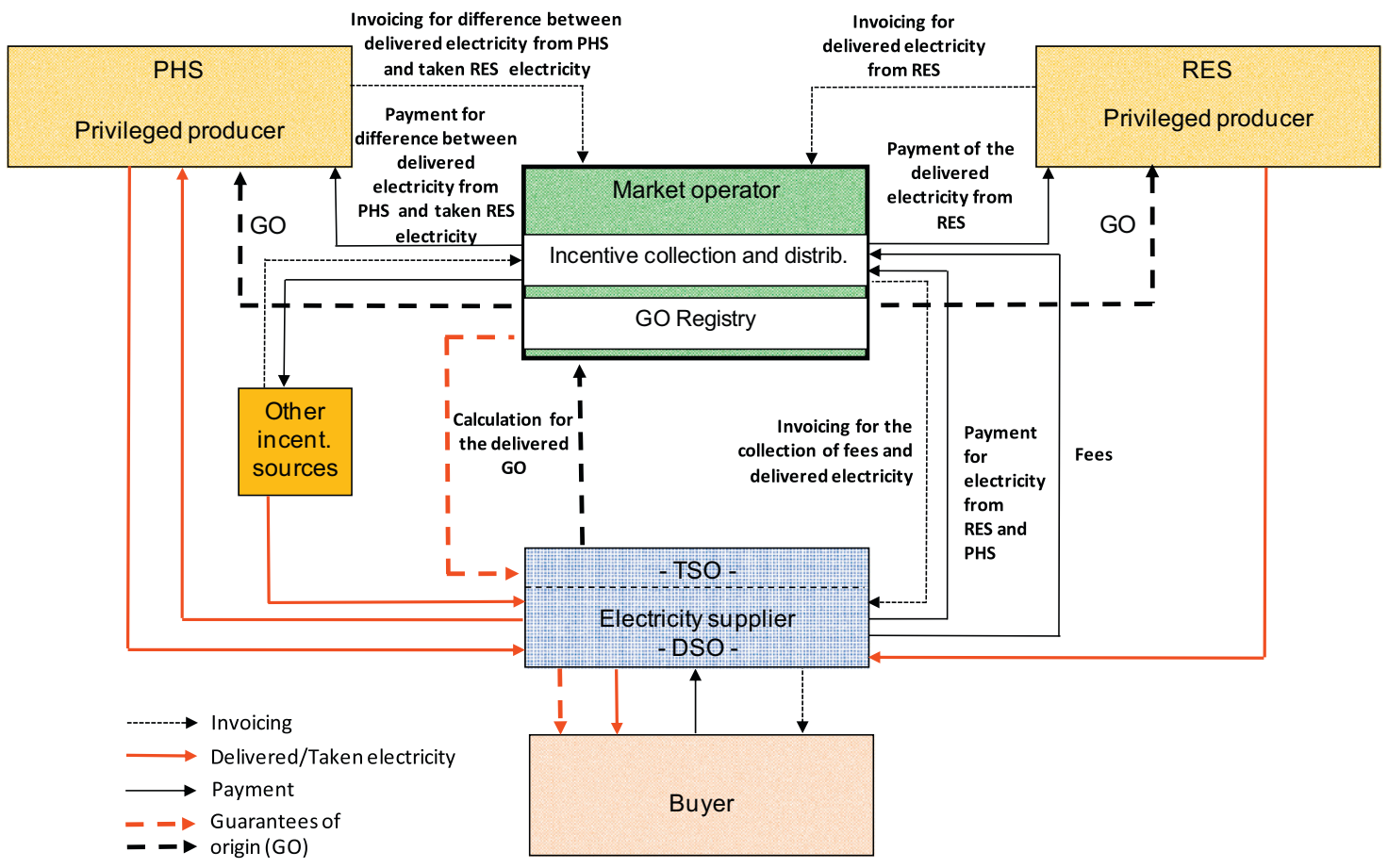

Fig. 3. Invoicing, payments and GO flows for FIT.

The electricity production cost of the turbine $E P C_{T}$ is defined under the assumption that the whole investment is considered as a means to provide guaranteed electricity supply during peak demand, hence wind energy sold at a fixed price is considered as inflow

$E P C_{T}=\frac{T I C_{W P S} R+O M C_{W P S}+C E_{c}-B E_{W}}{E_{T}}$

where $T I C_{W P S}$ is the total investment cost, $O M C_{W P S}$ is the operation and maintenance cost of the WHPS, $C E_{C}$ is the cost of conventional energy used for pumping, the actual energy production $E_{T}$ and $B E_{W}$ is the benefit from wind energy directly absorbed by the grid. If the market price is $p_{m}$, then

$C E_{C}=p_{m} E_{P: C}$

and if the fixed price for wind power is $p_{w}$, then

$B E_{W}=p_{W} E_{W, h: \rightarrow A}$

The electricity production cost of the conventional units $E P C_{C}$ is defined as

$E P C_{C}=\frac{T I C_{C} R+O M C_{C}}{E_{C}}$

where $T I C_{C}$ is the total investment cost of the essential conventional units, $O M C_{C}$ the operation and maintenance cost, and $E_{C}$ is the conventional energy production. The $O M C_{C}$ has a fixed cost part, a variable cost part and the fuel cost

$O M C_{C}=$ FixedCost + VariableCost + FuelCost

The electricity production cost of the electrical system EPCS is calculated as (assuming that the redundant units are uninstalled)

$E P C_{S}=\frac{T I C \times R+O M C}{E_{\text {Total }}}$

where TIC includes the cumulative investment cost of all power plants (essential conventional units, WHPS and wind farms outside the WHPS); the OMC includes the fixed cost, the variable cost and the fuel cost for the operation and maintenance of the system; and $E_{\text {Total }}$ is the total electricity demand.

\subsection{Feed-in tariffs for PHS in the Ios island case study}

The Ios case study will be used as an example to show how the proposed formulas for FIT work. Ios is an island in the Cyclades Complex and its electrical supply is part of the autonomous ParoNaxia system, which includes five main islands (Paros, Naxos, Ios, Sikinos, Folegandros) and some smaller islands. The only local power station is located in Paros with 10 Internal Combustion (IC) power units at a cumulative capacity of $61.4 \mathrm{MW}$. All the islands are interconnected but this system is considered venerable and centralised with high energy transportation losses and stability problems. The annual energy demand in Paros power system is estimated at 189.56 GWh, and the peak demand of $61.2 \mathrm{MW}$. Estimations for Ios refer to $12.6 \mathrm{GWh}$ with a peak demand of 3.9 MW. Ios has high wind potential and several existing water reservoirs, which are currently used for irrigation and may be cumulatively exploited for a PHS (Tsikalakis et al., 2009c).

The energy planning model $\mathrm{H}_{2}$ RES described in Lund et al. (2007) and Krajačić et al. (2009) has been used for modelling the system behaviour with installed PHS, a reduction of curtailed energy and operating hours of a PHS station. The $\mathrm{H}_{2}$ RES model is designed to support the Renewislands methodology (Duić et al., 2008) and is primarily used for balancing the hourly time series of water, electricity, heat and hydrogen demand, appropriate storages and supply. The main purpose of the model is energy planning for the islands and isolated regions, which operate as stand-alone systems. It can also serve as a planning tool for power producers using renewable energy sources that are connected to bigger power systems. Over time, the model has evolved and several new modules have been developed like wave, biomass, solar heat and desalination. Several papers describe the $\mathrm{H}_{2} \mathrm{RES}$ model and provide details of its operation (Duić et al., 2003, 2008; Duić and Carvalho, 2004; Lund et al., 2007). The main characteristic of $\mathrm{H}_{2} \mathrm{RES}$ model is that it uses technical data from equipment specifications, hourly meteorological data for intermittent sources, and according to the description in Duić et al. (2003), energy balancing is regulated by the equations.

In 2010, annual energy demand in the Paros power system was estimated at $246.3 \mathrm{GWh}$ and peak demand $<74.8 \mathrm{MW}$. 
The estmated hourly data for 2010 has been used in $\mathrm{H}_{2}$ RES. It was also assumed in the calculations that $18.3 \mathrm{MW}$ of wind was already installed in the system with an additional $13.5 \mathrm{MW}$ following installation of the PHS system (Table 3). With the limit on hourly wind penetration at $30 \%$ and without PHS and new wind installations, it was possible to satisfy $19 \%$ of yearly electricity demand while rejecting $30 \%$ of total wind potential. With the installation of PHS used for peak shaving at $82.5 \%$ of the dynamic weekly peak, it was possible to store $19 \%$ of all wind potential. In this case, PHS turbines supplied $3.5 \%$ of total demand and the capacity factor equalling $12 \%$. Under the same conditions and with $13.5 \mathrm{MW}$ of extra wind installed, capacity factor of turbines in PHS were increased to $20 \%$, accounting for a supply of $6 \%$ of total electricity demand. Wind share in the total demand was $23 \%$ with $34 \%$ representing the rejected potential. Fig. 4 presents a $\mathrm{H}_{2}$ RES Simulation of the power system on Paros in January. The high rejected potential is caused by low demand and favourable wind conditions.

Equipment cost for $T_{I I} C_{P H S}$ is calculated according Table 1 and does not take into account the cost of a lower reservoir, in its current state. The calculated $T_{I I} C_{P H S}$ is 6.8 mil $€$ and $\mathrm{OMC}_{\mathrm{PHS}}$ is $97,226 €$.

Table 4 and Fig. 5 present calculated stepped FIT in the Ios island case. Possible extra earnings for PHS owners if working in excess of 1750 hours are marked by a yellow colour.

This $F I T_{P H S_{W G O}}$ should be valid for PHS with 1 to $10 \mathrm{MW}$ of installed power turbines and for installations that already have lower reservoirs. Bigger systems and different configurations of PHS installations require additional calculations by using Eqs. (1)-(6) and Table 1.

For example, if the system on the Ios island requires the installation of a lower reservoir of the same size as the upper, the FIT for a load factor $<1750 \mathrm{~h}$ (or energy equivalent) should be at least $263 € / \mathrm{MWh}$.

If the same principle for designing a FIT is applied to case studies calculated by Caralis et al. (2010), the average FIT for all islands will be $422 € / \mathrm{MWh}$, in the cases where it was assumed that hydroturbine's peak demand supplies 50\% and 43\% energy contribution. The high FIT is due to different conditions for system design but also due to large differences on the islands sizes. Therefore, FIT

Table 3

Ios case study data

\begin{tabular}{|c|c|}
\hline Rated power of the turbine-MW & 8.0 \\
\hline Rated power of pumps-MW & 6.5 \\
\hline Capacity of the reservoir $-\mathrm{m}^{3}$ & 120,000 \\
\hline Installed power of $W T-M W$ & 18.3 \\
\hline Additional installed power of $W T-M W$ & 13.5 \\
\hline$E P C_{W G O}-€ / M W h$ & 87.42 \\
\hline$\eta_{P H S}$ & 0.696 \\
\hline$I$ & $15 \%$ \\
\hline$N$-payback years & 8 \\
\hline
\end{tabular}

for the Crete would be $269 € / M W h$ while for the Megisti Island it is $1065 € / \mathrm{MWh}$. It is interesting to note that if the discount rate in the design of FIT is set to $i=5 \%$ and the payback period set to 20 years as used by Caralis et al. (2010), the average FIT calculated for their case studies is $240 € / \mathrm{MWh}$ for a turbine size of PHS ranging from $1 \mathrm{MW}$ to $10 \mathrm{MW}$.

\subsection{Feed-in tariffs for WHPS Ios case study}

A more detailed financial analysis of the Greek hybrid system is given in Papathanassiou et al. (2008) and Papadopoulos et al. (2008). Some of the results for the Ios Case study are showed in Tsikalakis et al. (2009b) and Caralis et al. (2010).

The installation of WHPS contributes to a decrease in total EPC for the system and yearly savings are in the range of $2.2 \mathrm{mil} €$, including significant avoided emissions. Since WHPS also uses up to $6.3 \mathrm{GWh}$ of electricity from conventional pumping units, resulting in 1260 t of emitted $\mathrm{CO}_{2}$, so it is desirable to install a registry of GO to enable WHPS treatment as a RES power plant. In the both calculated cases for the Ios Island, despite storage installation there was still a certain amount of rejected wind generated electricity. If the amount of this rejected electricity is significant, wind producers should receive compensation for their losses. On the other hand, they could also share the burden in solidarity with consumers. Alternatively, compensation could be made to a special fund used for installations that reduce the amount of curtailment (storage and demand side management).

\subsection{Feed-in tariffs for hydrogen storage systems HSS}

The typical hydrogen storage system includes a water electrolysis unit, a hydrogen storage tank and a fuel cell. Electrolytic hydrogen is produced when excess energy is generated by renewable electricitygenerating technologies. Hydrogen is then stored in a gaseous form and can be used as a feedstock for the fuel cell in order to produce electricity when needed. Additionally, hydrogen can be used for transport purposes. In this case, the calculation of feed-in tariffs could be more complicated, since part of the payback should come from transport fuel prices.

Table 4

Proposed $F I T_{P H S_{W G O}}$ for PHS on Ios with the existing lower reservoir and $20 \%$ turbine load factor

\begin{tabular}{ll}
\hline $\begin{array}{l}\text { Working hours at full load } \\
\text { (or energy equivalent) }\end{array}$ & $F\left[T_{P H S_{W G O}}\right.$ [€/MWh] \\
\hline$<1750$ & 240 \\
$1750-2750$ & 132.5 \\
$>2750$ & 126.2 \\
\hline
\end{tabular}

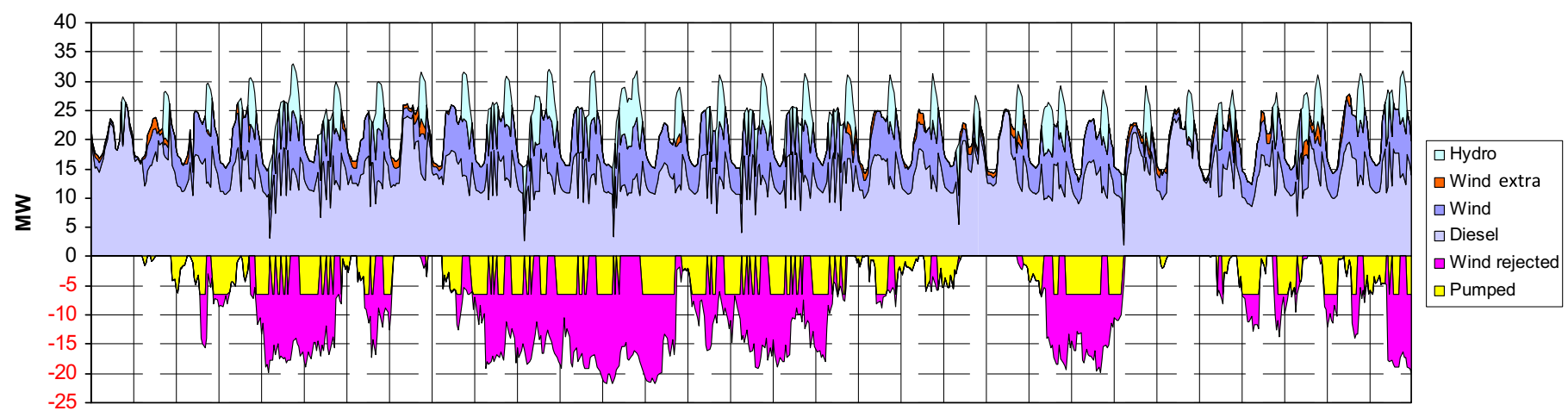

Fig. 4. $\mathrm{H}_{2}$ RES Simulation of the power system on the island Paros in January (development of PHS in IOS)—dynamic weekly peak. 


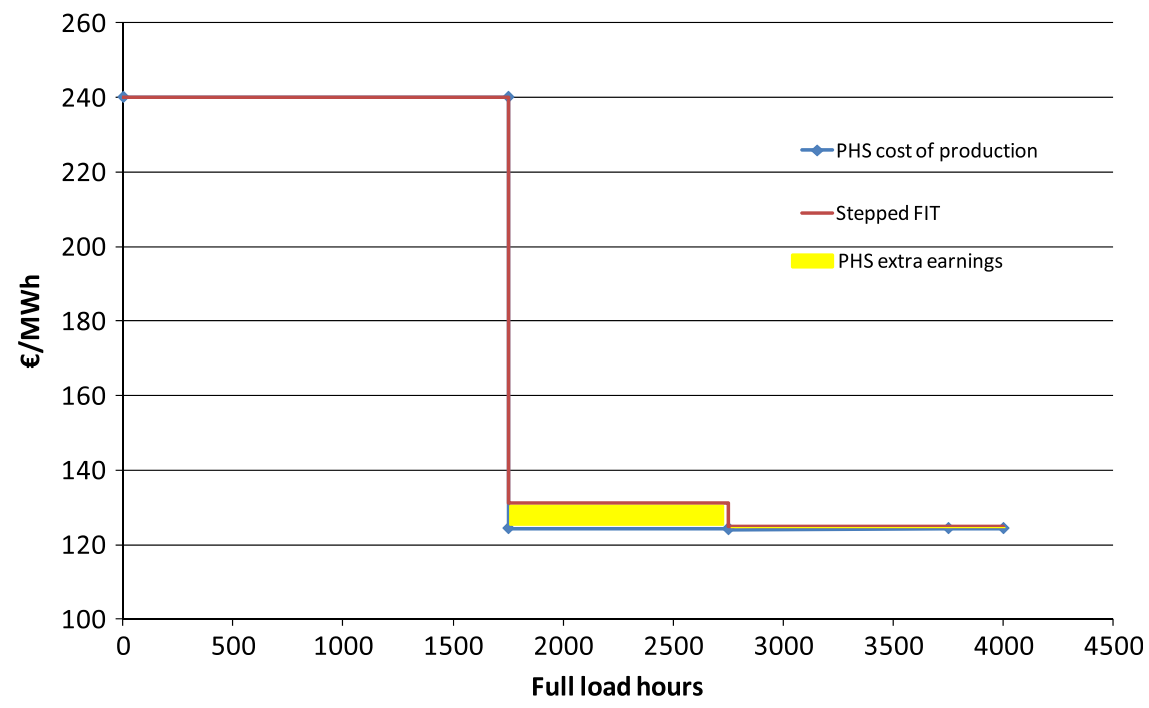

Fig. 5. Stepped FIT.

Installation costs of electrolyser, hydrogen storage, control system and compressor should be divided between electricity and transport costs.

FIT for hydrogen storage could be calculated in a similar manner to Eq. (3) for PHS

$F I T_{H 2 W G O}=\left(\left(\frac{T I C_{H 2} R+O M C_{H 2}}{E_{H 2}{ }_{W G O}}\right)_{W G O}+\left(\frac{E P C_{W G O}}{\eta_{H 2}}\right)_{W G O}\right)_{E_{H 2} W G O}$

where $\mathrm{TIC}_{\mathrm{H} 2}$ is the total cost of investment in HSS, $O M C_{\mathrm{H} 2}$ is the yearly operation and maintenance costs of HSS, $E_{H 2{ }_{W G O}}$ is the total delivered electricity to the network by HSS from electrolysed water. $E P C_{W G O}$ represents the price of RES electricity used in electrolysing water. $\eta_{\mathrm{H} 2}$ is the total efficiency of HSS and is calculated by

$\eta_{H 2}=\eta_{E L Y} \eta_{C} \eta_{F C}$

where $\eta_{E L Y}$ is the efficiency of electrolyser, $\eta_{C}$ is the efficiency of the compressor and hydrogen storage and $\eta_{F C}$ is the efficiency of fuel cells. $\eta_{\mathrm{H} 2}$ is an important factor and must be determined from technical documentation relating to the proposed hydrogen system or is taken as an average of values for $\eta_{\mathrm{H} 2}$.

Similar to the several levels of FIT for PHS, $F I T_{H 2_{W G O}}$ should also have several levels so that a single price is paid until the fuel cell reaches a desired level of a full load capacity. Subsequently, the load factor FIT is calculated from the following:

$F I T_{H 2 \text { WGO }}=1.02 \times \frac{E P C_{W G O}}{\eta_{H 2}}$

\subsection{Feed-in tariffs for HSS_Milos case study}

Milos is a Greek island situated on the south-western part of the country, specifically in the group of islands called Cyclades. Combining and introducing wind energy and hydrogen storage into the Milos power system has shown that a reduction on fossil fuel dependency, an improvement in supply security and a decrease in the production of harmful fossil fuel emissions are feasible and can be undertaken at a lower cost than current power generation (Parissis et al., 2009a, b). For Milos, the thermal units' capacity can be also reduced. Annual electricity demand for the Milos island is approximately 39,729 MWh with peak demand equal to 8.5 MW. In order to meet this demand, the existing power system includes 8 thermal generator sets with a total capacity of around $11.25 \mathrm{MW}$ and a small wind park comprising 3 wind turbines with a total installed
Table 5

Milos case study, equipment and $\mathrm{O} \& \mathrm{M}$ costs.

\begin{tabular}{|c|c|c|}
\hline Equipment & OE'M & Installation \\
\hline Fuel cell- $1 \mathrm{MW}$ & $4418 € /$ year & $1,500,000 €$ \\
\hline Electrolyser-2 MW & $50,000 € /$ year & $2,000,000 €$ \\
\hline Hydrogen storage tank $-4000 \mathrm{~kg}$ & $4000 € /$ year & $1,600,000 €$ \\
\hline \multicolumn{3}{|l|}{ Other data } \\
\hline$E P C_{W G O}-€ / \mathrm{MWh}$ & & 87.42 \\
\hline$E_{H 2 w G o}-\mathrm{kWh}$ & & $2,353,161$ \\
\hline$\eta_{\mathrm{H} 2}$ & & 0.3575 \\
\hline I & & $15 \%$ \\
\hline$N$-payback years & & 8 \\
\hline
\end{tabular}

capacity of $2.05 \mathrm{MW}$ and a $13.9 \%$ share in demand (Parissis et al., 2009a, b) (Table 5).

In this case, $F I T_{H 2_{W G O}}$ should be equal to or greater than $50 \mathrm{c} € / \mathrm{kWh}$ and should be paid until fuel cell reach full load capacity factor of $27 \%$ (or energy equivalent). Subsequently, the following load factor equation should be used to determine the feed-in tariff above desired load factor level

$F I T_{H 2_{W G O}}=1.02 \times \frac{E P C_{W G O}}{\eta_{H 2}}$

When not taking into account other benefits like (fuel savings, avoid emissions, etc.) described in detailed in Parissis et al. (2009a, b) the additional fee that should be collected in Milos in order to cover $F I T_{H 2 W G O}$ is $3 \mathrm{c} € / \mathrm{kWh}$. Furthermore, if all benefits are taken into account, the total price of electricity could be less by $0.1 \mathrm{c} €$ (Parissis et al., 2009a, b), meaning that, from the socio-economic point of view, there is no need for an extra fee. In the report provided by Parissis et al. (2009a, b), a detailed description of cost-benefit analysis and subsides required for hydrogen storage technologies is given.

3.7. Feed-in tariffs for batteries combined with PV systems for higher penetration levels

PV-batteries systems are the most common solution for off-grid applications. Thousands of such systems exist all over the world trying to meet rural electrification needs such as in the Sahara desert regions (Labed, 2008). However, these systems are out of the scope of this paper. 
Large battery installations have started becoming a reality such as the Battery Energy Storage Station in Alaska (Golden Valley Electric Association, 2010). It has been reported that 82 disconnection events have been avoided due to this the system; such events could have affected up to 310,000 customers for a maximum of 725 minutes of disconnection time during 2006.

Batteries have been considered as a means of providing support in power system dispatch (Yau et al., 1981), and have also been taken into account as models for providing a spinning reserve. Their potential impact on power quality issues should be also acknowledged (Swaminathan and Sen, 1998).

Here emphasis is given on grid-connected RES-batteries operating in autonomous power systems, like islands. Even more focus is given on evaluating FIT scheme for relatively high RES penetration levels. Under these operating conditions, batteries may be mainly required to reduce surplus electricity from RES, as well as provide partially support in improving adequacy of the power system (Tsikalakis et al., 2004) and smoothen as much as possible the output of the operating conventional units in the power system. With relatively low penetration, the impact of energy storage, here batteries, is expected to be more limited than in the case of higher PV penetration.

The reason for selecting PVs for the case study is the fact that the time to produce energy is easier determined than in the case of wind, during the daytime and the fact that PV cost is significantly higher per installed kW than wind. As explained in the Corvo case study, it may be preferable, in both operational and economic terms, to increase PV penetration not by installing additional PV capacity but by installing storage and more specific batteries, which is not a site-specific technology. The aim of the proposed FIT scheme is to provide incentives for combining batteries and RES in order to increase PV penetration on island power systems.

The parameters possibly affecting operation of the proposed system and which should be taken into account when designing FIT for batteries are the following:

The penetration level (PenLevel): Below a penetration level of about $12-13 \%$ (case specific which should be evaluated with power system simulation tools), FIT for storage can be unified since no additional RES production is injected into the grid. If the storage device provides other ancillary services such as frequency or voltage support, the remuneration tariff should be accordingly calculated, but this is beyond the scope of this paper.

The PV capacity (PVCap): As it increases and surpasses the capacity when curtailment takes place, the remuneration for additional PV should be reduced gradually since additional power system benefits will also be reduced. This will discourage and at the same time protect potential investors from building larger PV plants if problems exist in injecting power to the grid. At the same time, this could also lead investors to consider storage or deferrable loads in accommodating PV capacity and hence alleviate PV curtailment.

The Storage capacity in terms of Ah and their conversion to $k W h$ (BatCap): The storage value varies depending on the storage capacity. Even low values may provide aid in support the power system, whereas in some cases increasing storage capacity may significantly lead to very limited additional benefits. This will also be discussed in the case study. There should be additional incentives to balance batteries and PV capacity so that the benefits for the power system, especially in terms of fuel consumption and avoidance of emissions, are increased as much as possible,. Moreover, it should be stressed that batteries present highly non-linear behaviour. High charge/discharge rates, especially for lead acid batteries can drastically shorten their lifetime. Therefore, a higher capacity may be required to avoid such phenomena and prolong battery replacements periods.

The inverter capacity in terms of $k W$ (InvCap): This is closely related to BatCap, since these two parameters should correlate.
Usually the value of an inverter in $\mathrm{kW}$ ranges from $20 \%$ to $5 \%$ of the storage capacity. The impact of increasing inverter capacity above $10 \%$ of battery capacity (analogous to $\mathrm{C} 10$ parameter for batteries) is discussed. Potential benefits or drawbacks and ways of taking it into account under FIT are suggested for the specific case study.

The Fuel price (FuelPrice): When the units are identical and consume the same type of fuel, its evaluation is much easier than for multifuelled power systems. Changes in fuel prices should somehow be reflected on the FIT value. This will draw investors to power systems where fuel savings are greater. Investors might also endeavour to optimise production during hours when fuel benefits are higher, i.e. when more expensive units are expected to operate. However, caution should be taken so that FIT is not very sensitive to fuel price because fuel price fluctuation may create uncertainty in investors and have the opposite result.

Therefore, the mathematical formula for the FIT, apart from the considerations on the payback period and improved IRR, should take the above considerations into account like function 24 below. The correlation between various parameters, for some of which is very high, should be analysed by simulating power systems under high PV penetration for various energy storage capacities. Initial analysis can be made by using logistic tools that take into account not only RES potential and demand but also the technical minimum of the thermal units and reserve policy, i.e. how much load and PV production uncertainty will be considered by the power system operator

FIT = function(PVcap,BatCap,InvCAp,PenLevel,FuelPrice)

In order for FIT to become more effective in increasing PV penetration, storage should be charged using excess PV electricity. The discharge should aim in reducing conventional power plant operation time but the rate will be maintained below $12.5 \%$ of the battery capacity to prolong battery lifetime. The most critical value for changing FIT is the PenValue above which PV curtailment takes place. The suggestion is to have one FIT block for penetration values when no curtailment is expected. More focus and a more elaborate scheme, i.e. narrower steps, should be provided for higher penetration than this in order to take into account the increase in PV curtailment.

\subsection{Feed-in tariffs for PV and batteries under High penetration}

This case study represents of the Island of Corvo, one of the nine islands in the Azores archipelago, located in the western part of the archipelago. There is only one settlement, Vila Nova do Corvo, with about 400 inhabitants. The island's demand of approximately $1086 \mathrm{MWh}$ with a peak of $204 \mathrm{~kW}$ is met by two diesel gen-sets at $120 \mathrm{~kW}$ and two at $160 \mathrm{~kW}$, i.e. a total of $560 \mathrm{~kW}$. Usually, demand is met by two generators, one from each group. The fuel cost in Corvo is the highest in the entire archipelago, nearly 5 times the average in Azores and about $0.816 € /$ L for electricity production. On Corvo Island, the supply security is a real and frequent concern, since bad weather conditions commonly create oil shortages on the island. To reduce Corvo's dependency and secure supply, the implementation of an energy system that combines RES and storage can be a promising solution. The solar radiation potential on the island is $3.12 \mathrm{kWh} / \mathrm{m}^{2} /$ day. In all cases, a $50 \%$ uncertainty is considered for $\mathrm{PV}$ production while the load forecast error is considered a normal distribution function with a mean value $7.09 \%$ of the forecasted value, as explicitly described in Tsikalakis et al. (2009a).

First, potential tariff scheme used to reflect the case of PV curtailment is described. This will be the basis of calculations for part of the FIT referring, firstly to battery capacity and secondly to inverter capacity.

For the case of Corvo, the general form of the suggested FIT which depends on fuel price, is based on Eq. (25). FIT for the rest of 
the parameters will be calculated and Eq. (25) will be used for updating the FIT according to the change in Fuel Price (FP) as a last step

$F I T(F P)=F I T\left\{0.95+\frac{0.05 \times F P}{0.816}\right\}$

The PV capacity considered in the simulation, the initially expected production and the expected curtailment is shown Table 6. For simplicity, solar trackers have not been considered and the slope is equal to the geographical latitude at $31.5^{\circ}$ for the island. It is clearly shown that both PV curtailment and the percentage of PV production not delivered to the grid increase as PV capacity increases, consequently reducing the benefits for the island grid.

In order to calculate the FIT, the change in fuel consumption will be taken into account for various PenLev values in Table 7. For the first group of penetration level, the proposed FIT is the same with the highest provided in the Portugal. In this case, no additional production is planned. In the last column, $x$ represents total annual PV production. The fuel savings refer to the savings when production is increased from $12 \%$ to $16 \%$ and so on.

The additional income for the potential investor arising from increased installed capacity, should be equal to the increase in savings for the power systems, so that the clear economic position for the power system remains the same with conditions that do not lead to curtailment. Subsequently, the potential investor is encouraged to optimise the operation of the PV plant and gradually increase its capacity following any increase in demand on the island.

\subsubsection{Considering batteries}

Various values of lead acid battery capacity, BatCap, have been considered in the simulation runs with Inverter capacity (InvCap) at $1 / 10$ th of BatCap, as given in Table 8 . The update in battery content as a function of time depends on the exchange with the island grid, based on Peukert's Eq. (26)

$I^{n} \times T i=$ constant

where $I$ is the charge/discharge battery current, $n$ is the Peukert number in the range $1.05-1.40$, here taken as 1.30 , and $T i$ is the charge or discharge period.

The remuneration of batteries on annual basis takes the form of providing a service,, and is based on BatCap values and the fuel savings achieved during operation.

Table 6

PV capacity considered in the simulations and expected PV curtailment.

\begin{tabular}{ccc}
\hline $\begin{array}{l}\text { Installed capacity } \\
\text { [kW] }\end{array}$ & $\begin{array}{l}\text { Expected PV production } \\
\text { [MWh/yr] }\end{array}$ & $\begin{array}{l}\text { Expected PV curtailment } \\
\text { [MWh/yr] }\end{array}$ \\
\hline 0 & 0 & 0 \\
15.5 & 14.9 & 0 \\
155 & 149.1 & 18.51 \\
185 & 178 & 34 \\
283 & 271.3 & 86.5 \\
400 & 384.8 & 190.3 \\
\hline
\end{tabular}

In this case, storage mainly helps in providing part of the necessary spinning reserve for operation of the power system. Little exchange with the power grid is expected. Even a small battery capacity can significantly improve the economics of the power system with benefits somewhat falling as battery capacity increases. The benefits in both cases, with and without PVs, evaluation and the proposed remuneration scheme for battery capacity is shown in Table 9 .

The way in which batteries assist in increasing energy injected into the grid and reducing PV power curtailment is shown in Fig. 6. The increased grid injection helps in reducing fuel consumption on the island as shown in Fig. 7. These benefits are reduced for all cases when battery capacity exceeds $320 \mathrm{kWh}$, mainly for a PV capacity below $200 \mathrm{~kW}$. It is almost as beneficial to increase battery capacity for $400 \mathrm{~kW}$ installed PV capacity from $640 \mathrm{kWh}$ to $960 \mathrm{kWh}$ as it is to increase battery capacity from 320 to $640 \mathrm{kWh}$ for a $283 \mathrm{~kW}$ installed PV capacity. Such service of batteries should be accordingly remunerated in order to entice investors to invest more on storage rather than on PVs when increased penetration is expected. Part of the additional benefits for the power system have been remunerated due to additional PV production based on the formulas presented in Table 7.

The difference between the savings in fuel and the PV remuneration is used as the basis for calculating suggested tariff schemes for batteries at various penetration levels.

\subsubsection{Doubling inverter capacity}

Additional analysis is linked to inverter capacity. Increasing inverter capacity allows, in case of emergency, to have higher power provision from the battery helping in increasing adequacy of the power system until a new unit is committed. This reduces uncertainty for the power system operators and under circumstances can lead to avoidance of committing additional operating units. Additionally helps in increasing the PV excess electricity that can be stored. As a policy, to avoid very high rates of exchange, which would shorten battery lifetime, the rate of charge/discharge under steady state conditions is at maximum the $12.5 \%$ of the battery capacity.

In all cases increasing inverter capacity, fuel consumption will be reduced as shown in Fig. 8 .

As in the case of batteries, the investor willing to increase inverter capacity up to $20 \%$ of the battery capacity is remunerated as a service provision per year. When PV curtailment is expected, the additional PV injection due to the higher capacity exchange rate has

Table 8

Capacity limits for the considered batteries.

\begin{tabular}{lll}
\hline $\begin{array}{l}\text { Capacity } \\
\text { range (CR) }\end{array}$ & $\begin{array}{l}\text { Upper limit (Lmt) of battery } \\
\text { capacity [kWh] }\end{array}$ & $\begin{array}{l}\text { Upper limit of inverter } \\
\text { capacity [kW] }\end{array}$ \\
\hline 1 & 40 & 4 \\
2 & 80 & 8 \\
3 & 160 & 16 \\
4 & 320 & 32 \\
5 & 640 & 64 \\
6 & 960 & 96 \\
\hline
\end{tabular}

Table 7

FIT for PVs on Corvo without storage.

\begin{tabular}{|c|c|c|c|}
\hline Penetration level (PenLev) [\%] & PV production [MWh/yr] (x) & Fuel savings [t/additional MWh injected/yr] & Proposed FIT [€/MWh] \\
\hline $0-12$ & $0-130$ & No curtailment/not considered & 450 \\
\hline \multirow[t]{2}{*}{$12-16$} & $130-173$ & 0.21 & $450 \times 130+0.21 \times F P(x-130)$ \\
\hline & & & $\begin{array}{c}x \\
\end{array}$ \\
\hline \multirow[t]{2}{*}{$16-25$} & $173-271$ & 0.204 & $\underline{380 \times 73 \times 173+0.204 \times F P(x-173)}$ \\
\hline & & & $x$ \\
\hline \multirow[t]{2}{*}{$25+$} & 271 & 0.169 & $303 \times 25 \times 271+0.169 \times F P(x-271)$ \\
\hline & & & $x$ \\
\hline
\end{tabular}


Table 9

The remuneration scheme for various battery capacity levels at a penetration level below $12 \%$.

\begin{tabular}{|c|c|c|}
\hline \multirow[t]{2}{*}{ CR } & \multicolumn{2}{|l|}{ Remuneration [ $€ / k W h$ of battery] } \\
\hline & Without PV & With PV \\
\hline $\begin{array}{l}1 \\
2\end{array}$ & $\begin{array}{l}82.1 \times \text { BatCap } \\
\frac{82.1 \times \operatorname{Lmt}(1)+3.33(\text { BatCap}-\operatorname{Lmt}(1))}{\text { BatCap }}\end{array}$ & $\begin{array}{l}53.8 \times \text { BatCap } \\
\frac{53.8 \times \operatorname{Lmt}(1)+19.1(\text { BatCap }-\operatorname{Lmt}(1))}{\text { BatCap }}\end{array}$ \\
\hline 3 & $\frac{41.7 \times \operatorname{Lmt}(2)+38.6(\text { BatCap }-\operatorname{Lmt}(2))}{\text { BatCap }}$ & $\frac{36.45 \times \operatorname{Lmt}(2)+35.06(\text { BatCap }-\operatorname{Lmt}(2))}{\text { BatCap }}$ \\
\hline 4 & $\frac{40.12 \times \operatorname{Lmt}(3)+11.96(\text { BatCap}-\operatorname{Lmt}(3))}{\text { BatCap }}$ & $\frac{35.75 \times \operatorname{Lmt}(3)+13.5(\text { BatCap}-\operatorname{Lmt}(3))}{\text { BatCap }}$ \\
\hline $5-6$ & $\frac{26.04 \times \operatorname{Lmt}(4)+0.1(\text { BatCap }-\operatorname{Lmt}(4))}{\text { BatCap }}$ & $\frac{24.63 \times \operatorname{Lmt}(4)+0.2(\text { BatCap-Lmt }(4))}{\text { BatCap }}$ \\
\hline
\end{tabular}

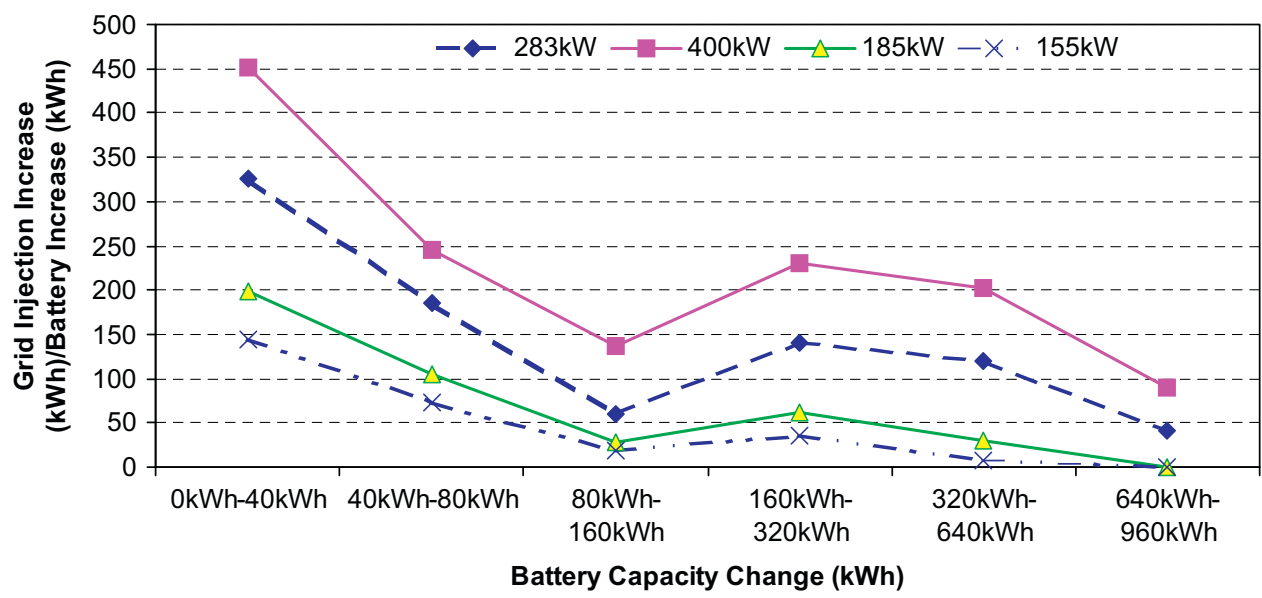

Fig. 6. Grid Injection increase due to change in battery capacity for various PV capacity levels.

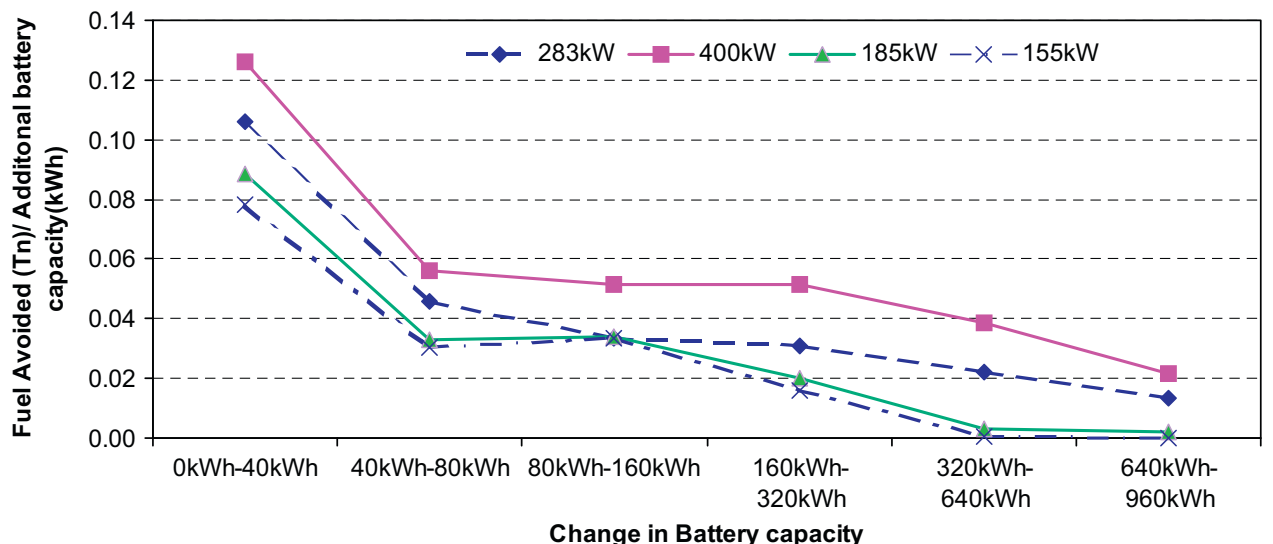

Fig. 7. Fuel avoided due to change in battery capacity.

been remunerated using the scheme described in Table 7 . The additional benefits, that have not been covered by the formulas in either Table 7 or Table 10 should be provided as remuneration for the increase of inverter capacity. The formulas describing the additional remuneration are based on the simulation run for Corvo are provided in Table 11. InvCap is the increase in inverter capacity which should be linked to both battery capacity and the existing inverter whose capacity the investor would like to double.

The power system benefits are negligible for low capacity PVs where no PV curtailment occurs, and in instances of high inverter capacity. For lower inverter and battery capacities, the additional economic benefits on Corvo are significant and no additional remuneration is provided to PVs since no production changes occur. Thus, additional remuneration should be provided only when increasing an inverter's capacity to obtain these benefits as described in Table 12 .

\subsubsection{An illustrative comparative example}

The following two examples presenting the same PV penetration, $15.8 \%$ of the annual demand, show the efficiency of the proposed schemes based on the annual simulation results.

(a) One $283 \mathrm{kWp}$ PV with 99.5 MWh undelivered to grid

(b) One $185 \mathrm{kWp}$ PV combined with a $320 \mathrm{~kW}$ battery capacity and $64 \mathrm{~kW}$ inverter. Finally, only 6.6 MWh of PV production is not delivered to the island power system as opposed to the 


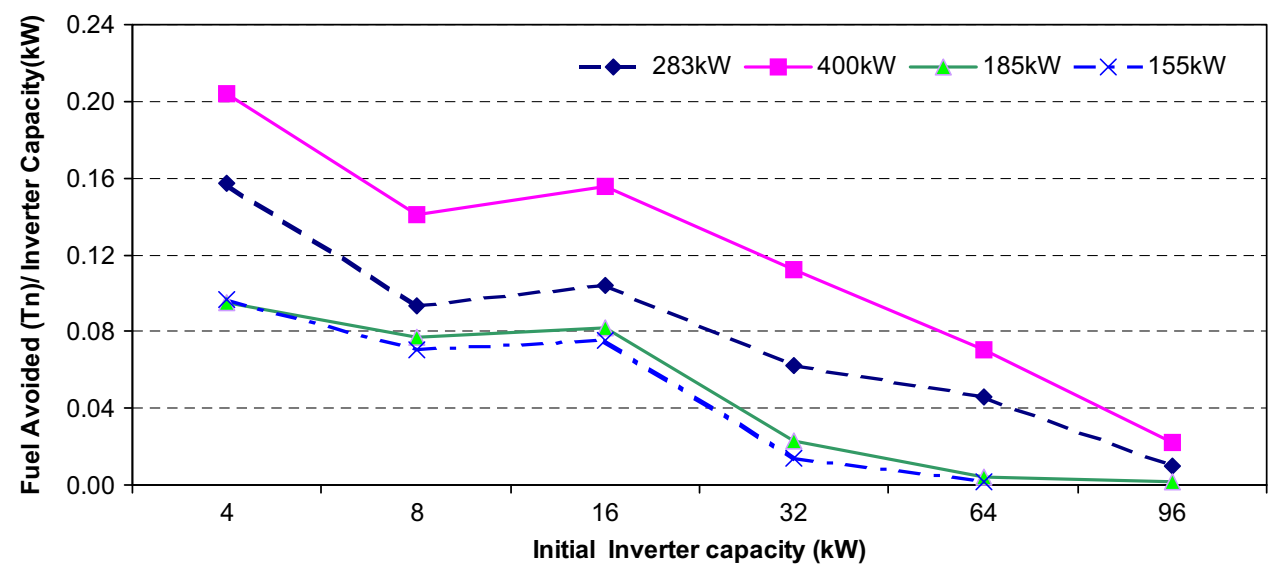

Fig. 8. Fuel avoided when inverter capacity is doubled as inverter capacity changes for various PV levels.

Table 10

The remuneration scheme for batteries at penetration levels above $12 \%$ for various battery capacity and penetration levels.

\begin{tabular}{|c|c|c|c|}
\hline \multirow[t]{2}{*}{ CR } & \multicolumn{3}{|l|}{ Remuneration [ $€ / k W h$ of battery] } \\
\hline & PenLev $=12-16 \%$ & PenLev $=16-25 \%$ & PenLev $>25 \%$ \\
\hline 1 & $35.42 \times$ BatCap & $27.3 \times$ BatCap & \\
\hline 2 & $\frac{35.42 \times \operatorname{Lmt}(1)+8.79(\text { BatCap}-L m t(1))}{\text { BatCap }}$ & $\frac{27.3 \times \operatorname{Lmt}(1)+5.13(\text { BatCap}-\operatorname{Lmt}(1))}{\text { BatCap }}$ & \\
\hline 3 & $\frac{22.105 \times \operatorname{Lmt}(2)+39.88(\text { BatCap}-\operatorname{Lmt}(2))}{\text { BatCap }}$ & $\frac{16.22 \times \operatorname{Lmt}(2)+16.04(\text { BatCap }-\operatorname{Lmt}(2))}{\text { BatCap }}$ & $\mathrm{N} / \mathrm{A}$ \\
\hline 4 & $\frac{31 \times \operatorname{Lmt}(3)+2.24(\text { BatCap }-\operatorname{Lmt}(3))}{\text { BatCap }}$ & $\frac{16.13 \times \operatorname{Lmt}(3)+1.16(\text { BatCap}-\operatorname{Lmt}(3))}{\text { BatCap }}$ & \\
\hline 5 & $\frac{16.62 \times \operatorname{Lmt}(4)+1.89(\text { BatCap}-\operatorname{Lmt}(4))}{\text { BatCap }}$ & $\frac{8.64 \times \operatorname{Lmt}(4)+1.44(\text { BatCap}-\operatorname{Lmt}(4))}{\text { BatCap }}$ & $\frac{10.79 \times \operatorname{Lmt}(4)+2.18(\text { BatCap}-\operatorname{Lmt}(4))}{\text { BatCap }}$ \\
\hline 6 & & & $\frac{7.08 \times \operatorname{Lmt}(5)+5.53(\text { BatCap}-\operatorname{Lmt}(5))}{\text { BatCap }}$ \\
\hline
\end{tabular}

Table 11

The remuneration scheme for inverters for penetration level above $12 \%$ for various inverter capacity values.

\begin{tabular}{|c|c|c|c|}
\hline \multirow[t]{2}{*}{ CR } & \multicolumn{3}{|l|}{ Remuneration [ $€ / k W$ of inverter] } \\
\hline & PenLev $=12-16 \%$ & PenLev $=16-25 \%$ & PenLev > 25\% \\
\hline 1 & $17.68 \times \operatorname{InvCap}$ & $3.15 \times \operatorname{InvCap}$ & \\
\hline 2 & $\frac{17.68 \times \operatorname{Lmt}(1)+35.37(\operatorname{InvCap}-\operatorname{Lmt}(1))}{\operatorname{InvCap}}$ & $\frac{3.15 \times \operatorname{Lmt}(1)+10.67(\operatorname{InvCap}-\operatorname{Lmt}(1))}{\operatorname{InvCap}}$ & N/A \\
\hline 3 & $\frac{26.52 \times \operatorname{Lmt}(2)+41.46(\operatorname{Inv} C a p-\operatorname{Lmt}(2))}{\operatorname{InvCap}}$ & $\frac{6.91 \times \operatorname{Lmt}(2)+30.21(\operatorname{InvCap}-\operatorname{Lmt}(2))}{\operatorname{InvCap}}$ & \\
\hline 4 & $\frac{33.99 \times \operatorname{Lmt}(3)+2.05(\operatorname{InvCap}-\operatorname{Lmt}(3))}{\operatorname{InvCap}}$ & $\frac{18.56 \times \operatorname{Lmt}(3)+2.61(\operatorname{InvCap}-\operatorname{Lmt}(3))}{\operatorname{InvCap}}$ & $\frac{18.56 \times \operatorname{Lmt}(3)+2.61(\operatorname{InvCap}-\operatorname{Lmt}(3))}{\operatorname{InvCap}}$ \\
\hline 5 & $\frac{33.99 \times \operatorname{Lmt}(4)+2.05(\operatorname{InvCap}-\operatorname{Lmt}(4))}{\operatorname{InvCap}}$ & $\frac{10.59 \times \operatorname{Lmt}(4)+1.61(\operatorname{InvCap}-\operatorname{Lmt}(4))}{\operatorname{InvCap}}$ & $\frac{10.59 \times \operatorname{Lmt}(4)+20.44(\operatorname{InvCap}-\operatorname{Lmt}(4))}{\operatorname{InvCap}}$ \\
\hline 6 & & & $\frac{15.52 \times \operatorname{Lmt}(5)+7.74(\operatorname{InvCap}-\operatorname{Lmt}(5))}{\operatorname{InvCap}}$ \\
\hline
\end{tabular}

expected 34.5 MWh, taking into account no form of storage with the same PV capacity.

Even though PV production finally delivered to the grid is the same for both options, the benefits for the power system increases by $4700 €$ for solution B compared to solution A. Hence, additional remuneration should be provided for the battery service and more incentives for increasing capacity of the inverter to $20 \%$ of the battery capacity.

According to Table 7, remuneration for PVs should be $382.8 € /$ MWh for both case studies. According to Table 10, Scenario B should receive remuneration for batteries equal to $16.62 € / \mathrm{kWh}$ and since Inverter Capacity is increased, this should be remunerated according to Table 11 at $18.02 € / \mathrm{kW}$. Assuming the following installation costs, $500 € / \mathrm{kW}$ for the inverter, $150 € / \mathrm{KWh}$ for storage 
Table 12

The remuneration scheme for various inverter capacity values at penetration levels below $12 \%$.

\begin{tabular}{ll}
\hline $\boldsymbol{C} R$ & Remuneration [€/kW of inverter] \\
\hline 1 & $30.9 \times \operatorname{InvCap}$ \\
2 & $\frac{30.9 \times \operatorname{Lmt}(1)+142.17(\operatorname{InvCap}-\operatorname{Lmt}(1))}{\operatorname{InvCap}}$ \\
3 & $\frac{86.53 \times \operatorname{Lmt}(2)+87.51(\operatorname{InvCap}-\operatorname{Lmt}(2))}{\operatorname{InvCap}}$ \\
4 & $\frac{87.02 \times \operatorname{Lmt}(3)+0.6(\operatorname{InvCap}-\operatorname{Lmt}(3))}{\operatorname{InvCap}}$
\end{tabular}

and $4000-7000 € / \mathrm{kW}$ for PV installation, the IRR for both these solutions can be calculated by neglecting all other subsidies. The project lifetime is 20 years and two battery replacements are planned within this period (6-7 years battery lifetime).

For solution A, the maximum IRR (Internal Rate of Return) is $1.46 \%$, however if $\mathrm{PV}$ installation prices exceed $5000 € / \mathrm{kW}$ the project cannot be paid back.

For solution B, the maximum IRR is $4.77 \%$, while if installation prices exceed $6000 € / \mathrm{kW}$, the investment becomes economically unfeasible. Therefore, in addition to much higher IRR than solution A, solution B is much less sensitive to PV installation costs.

Even if $P V$ production was remunerated at $450 € / M W h$ for solution A, the IRR would be $3.16 \%$ and the maximum PV installation price would have been $5500 € / \mathrm{kW}$, providing no additional benefit to the power system.

Thus, the proposed tariff scheme clearly improves the economics for both the investor and the power system, if PV penetration on Corvo is to be increased to such an extent so as to inevitably result in the curtailment of PV production. This proposed schemes manage to give incentives for considering storage as one of the solutions in increasing penetration rather than simply adding PV capacity and curtailing its production.

\subsection{Feed-in tariffs for RES meeting $100 \%$ of desalination systems requirements}

Desalination via Reverse Osmosis (RO) is not a direct electricity storage method as the above studied technologies. Nevertheless, it is a load whose output can be controlled easier than other loads and far more importantly, it produces a commodity that can be easily and safely stored, i.e. potable water. Simultaneously, it is a load requiring significant energy demand. For every $1 \mathrm{~m}^{3}$ of desalinated water approximately $2.8-4.5 \mathrm{kWh}$ of electricity is required when energy recovery devices are connected to brine stream. The mentioned figures also depend on water salinity and plant design. The energy share of water production costs can range from about $30 \%$ to $50 \%$, depending on energy costs, process types and design.

When compared to other desalination methods, e.g. evaporation or thermal process, RO provides significant flexibility in adding capacity and is available in various sizes from a few $\mathrm{kW}$ of consumption and a few litres of potable water per hour up to tens of cubic metres and a capacity of some hundreds of kWs. The modular nature of this technology and its flexibility makes it an ideal candidate for studying its operation with RES in more detail.

RO desalination has been used in previous articles by the authors for utilising excess electricity by RES in island power systems, either for Cyprus (Tsikalakis et al., 2009c), the Greek islands of Milos (Tsikalakis et al., 2009b) and Kythnos (Psychogiopoulos et al., 2008) and the Cape Verde (Segurado et al., 2011). All of these papers present very promising results on the potential benefits from the co-operation of desalination with RES especially in the potential wind power curtailment reduction. These benefits are viewed not only from the aspect of the power system but also from the aspect of RES investors, even if they have not invested in a desalination facility. Additional benefits could be achieved by coupling RES desalination with the PHS system.

Water requirements on island power systems increase during the summer period due to higher population numbers and higher average temperatures. During the same period, islands have much higher demand compared to the winter period, making Desalination an even more difficult load to cope with Hatziargyriou et al. (2006). Fortunately, PV production during summer time generally increases, achieving an efficient compensation for increased demand caused by desalination.

The above characteristics for the desalination load have led us to further analyse a potential FIT scheme for desalination customers willing to meet $100 \%$ of their demand via PVs and the approach to be followed in implementing this.

Our case study is the small island power system on Mljet close to the Dalmatian Coast. An additional reason for selecting PVs is the restriction against installing wind power on Croatian islands. On the island, there are already three small RO desalination plants while the major electricity and water consumer on the island, Hotel Odissej, transports water from the mainland to meet its demand.

\subsection{Feed-in tariffs for desalination systems in PV_-Mljet case study}

Mljet is located in the southern Dalmatian archipelago, $30 \mathrm{~km}$ west from Dubrovnik and south of the Peljesac Peninsula, separated from the Peninsula by the Mljet channel. Mljet is an elongated island, with an average width of 3 and $37 \mathrm{~km}$ long, encompassing a total island area of $100.4 \mathrm{~km}^{2}$. The island economy is based on farming, viticulture, wine making, olive growing, cultivation of medicinal herbs, fishing and tourism. The estimated island's peak demand is $1580 \mathrm{~kW}$ in August, while the total demand of $4.4 \mathrm{GWh}$ is covered by two $10 \mathrm{kV}$ submarine cables linked to mainland Croatia.

The case study considered is the installation of PVs on the premises of the existing desalination plants, interconnected to the island's distribution grid.

Table 13 provides the names and the annual energy demand of the existing desalination plants. In the same table, the PV capacity for meeting $100 \%$ of demand is provided. More detailed technical description of similar desalination plant installed on the nearby island of Lastovo is given by Sambrailo and Ivić (2000) and Sambrailo et al. (2005).

The current tariff scheme for remunerating PV production is provided in Table 14. Remuneration is reduced as installation capacity increases, but the reduction is not proportional, especially for a capacity greater than $30 \mathrm{~kW}$. Thus, the PV investor does not have the incentive to add small additional capacities above $30 \mathrm{~kW}$ like some of the PVs in

Table 13

Desalination plants data.

\begin{tabular}{llll}
\hline & \multicolumn{2}{l}{ Desalination plants } \\
\cline { 2 - 4 } & Kozarica & Sobra & Blato \\
\hline Energy demand [MWh] & 12.54 & 51.14 & 62.27 \\
Installed PV capacity [kW] & 9.42 & 40.8 & 44.9 \\
\hline
\end{tabular}

Table 14

Remuneration of RES in Croatia.

\begin{tabular}{ll}
$10 \boldsymbol{k W}<P V[€ c t / k W h]$ & 46.81 \\
$\mathbf{1 0} \boldsymbol{k W}<P V<\mathbf{3 0} \boldsymbol{k W}[€ c t / k W h]$ & 41.3 \\
$P V>\mathbf{3 0} \boldsymbol{k W}[€ c t / k W h]$ & 28.91 \\
\hline
\end{tabular}


Table 15

Comparison of new and old tariff scheme in Croatian desalination plants.

\begin{tabular}{llll}
\hline & \multicolumn{2}{l}{ Desalination plants } & \\
\cline { 2 - 4 } & Kozarica & Sobra & Blato \\
\hline Old FIT [ $€$ ct/kWh] & 46.81 & 28.91 & 28.91 \\
Updated FIT [€ct/kWh] & 46.81 & 38.02 & 37.18 \\
\hline
\end{tabular}

Table 16

Financial indices for PVs at existing desalination plants with both current and proposed tariff scheme.

\begin{tabular}{lll}
\hline & IRR [\%] & Payback [yr] \\
\hline Kozarica (same tariff) & 8.05 & 15.17 \\
Blato old tariff & 0.975 & 61.93 \\
Sobra old tariff & 0.786 & Not paid back \\
Blato proposed tariff & 4.11 & 28.30 \\
Sobra proposed tariff & 4.14 & 28.08 \\
\hline
\end{tabular}

Table 13. It should be noted that a $31 \mathrm{~kW}$ PV plant receives a $27 \%$ lower annual remuneration when compared to a $30 \mathrm{~kW}$ PV installation. This is clearly not justified by the almost negligible reduced benefits of a more "centralised" installation of PVs.

The proposed Feed-in tariff scheme for investors willing to invest on PVs when they have already installed desalination plants is described in the following:

$F I T=F I T_{b} \frac{b_{2}}{C a p}+F I T_{c} \frac{\left(C a p-b_{2}\right)}{C a p}$

In this case, if $b$ and $c$ are two successive installation capacity ranges according to Table 14, Cap is the installed PV capacity and $b_{2}$ is the upper limit of capacity for applying the previous FIT scheme. The new fixed FIT price for the PV owner is obtained from the linear regression formula. Thus, the higher the PV capacity, the lower the FIT price, as the current remuneration scheme suggests, but not to the extent so as to discourage installers from additional capacity at a park.

Table 15 compares the FIT for the PVs at the desalination plants before and after the introduction of the proposed tariff scheme.

Assuming an installation cost for all the required equipment (including converters, etc.) equivalent to $7000 € / \mathrm{kW}$ at a $6 \%$ discount rate, the Financial Indices for PV installation can be calculated as described in Table 16 for both the proposed and the current tariff scheme.

Clearly the current tariff scheme proves to be inefficient for those investors willing to promote "green" electricity and a clean way of producing water for the local population.

The updated tariff scheme provides much more reasonable pay back periods, although somewhat above the usual lifetime of PVs, and with a small installation capacity or subsidy the payback period can be reduced even further. It should be noted that the proposed FIT has equivalent results when reducing or subsidising the installation cost by at least $25 \%$.

Coincidentally, losses avoidance will be $3.3 \mathrm{MWh}$ and the corresponding emissions avoidance will be $99.6 \mathrm{tCO}_{2}$. The achieved economic benefit for the power system will be in the order of $50.87 € / \mathrm{MWh}$, lower than the additional FIT tariff. However, the additional employment created, emissions avoidance and the potential decrease in installation costs justify this deviation in the FIT price.

\section{General conclusions and recommendations}

In this paper, feed-in tariffs for various energy storage and desalination systems are discussed along with a proposal for their application in regions most suited for such application. Widespread use of energy storage could optimise the existing assets on the market, increasing their profit and worth.

FIT design for both concepts of storage system application is rather simple and it can be easily performed by Energy Regulatory Agencies or Electricity Market Operators with the assistance of experts from TSOs and DSOs. After successful application on the islands and outermost regions, tariffs for energy storage should be also applied to mainland power systems.

To increase RES-E penetration, other technologies like thermal energy storage, cold storage, electric vehicles or V2G could be supported by FIT, similar to those presented in this paper. These technologies should be supported since in the long-term they could provide greater benefits to communities, outweighing the effects of their cost. The hypothesis has been already proven by FIT for wind energy. Many experts claim that in most places wind power would even now be competitive if conventional energy stopped receiving hidden subsidies. If the costs of fossil fuels were to reflect all the environmental damage they cause, such fuels would actually be much more expensive. Another issue overcome by FIT is market competition between RES and conventional technologies. Once a wind turbine is installed, market competition cannot make it to work more efficiently. This implies a relatively high investor risk on an uncertain and competitive market (Meyer, 2003). Wind power costs can be affected by the electricity market by up to $20 \%$ at the most in terms of total production costs. Whereas production costs for coal-based electricity production can be influenced by more than $50 \%$ by the market (Hvelplund, 2006). Competition in the area of wind power mainly relates to the wind turbine producers with competition resulting in an $80 \%$ decrease in wind power costs during the last 20 years (Meyer, 2003). Similar to wind technology FIT for storage could lead to competition on the producers' side.

In the both calculated case studies for Ios Island and use of PHS and WPHS, despite a storage installation, a certain amount of rejected wind electricity is anticipated. If this amount is significant, wind producers should then receive compensation for their losses or on the other hand, they could share the burden with consumers. Alternatively, compensation could be directed to a special fund used for installations, which would reduce the amount of rejected production (storage, demand side management). It has also been shown that RES owners present clear benefits for investing a proportion of the resources on desalination or provide part of their profit to desalination plant owners in order to reduce critical excess electricity production (Tsikalakis et al., 2009c).

Prior to application of the scheme, it is important to both solve other potential barriers and evaluate domestic conditions such as potential of renewable energy resources and geographical conditions, current and future political environment, economic environment and technological preconditions. The FIT should reflect the desirable and possible rates of increase in RES utilisation in terms of capacity and share in the energy mix. Another parameter to be checked is the state of the electricity grid and the type of connection across the area.

Furthermore, it is expected that the Regulator analyse financial schemes and according to information received from utility companies (operating costs, base rate, amortisation depreciation, investment, taxes and rate of return) offer proposals for new schemes every 4-5 years.

Identifying comparable conditions in other countries where a financial mechanism for RES hybrid and storage systems (for example Greece) has already been implemented would be very helpful.

According to Article 5 of DIRECTIVE 2009/28/ (The European Parliament and the Council of the European Union, 2009), production of electricity from water in pumped storage units that has previously been pumped uphill is not treated as a renewable 
electricity, and cannot thus receive guaranties of origin that will be recognised at the EU level and accepted by the European Commission. Moreover, according to the same EU Directive, electricity used by the pumped storage is included in the final gross energy consumption, which means that if used, it will increases the amount of energy from renewable sources that should be achieved by the year 2020. On the other hand, all electricity produced from renewable energy sources (directly delivered to the grid or used to pump water uphill or for any other dump load) will be treated in the final gross electricity consumption as renewable energy sources without taking into account storage efficiencies. This regulation avoids the twofold counting of RES-E but energy storage is also discriminated as all stored energy is treated as consumption. The introduction of FIT for storages with traceable GO could lead to better system designs and improved efficiencies. Consequently, FIT for storage should only be used in a system where traceable GO exists in order to make sure that the storage is not used to store electricity from conventional power plants and thereby just adding a loss in efficiency if the feed-in tariff for "discharging" the storage may be too high.

Batteries can be used for increasing penetration in small island systems with PVs. The proposed FIT remunerates batteries and inverters as a service and not as an energy flow taking also into account the potential economic and operational benefits for the power system. The proposed FIT scheme tries to make PV investors consider storage if they want to increase their production share in the island power system above the level which could lead to power curtailment. Such a scheme would discourage investors from adding PV capacity that will neither be fed into the grid nor significant benefits to the power system will bring. The efficiency of the proposed FIT scheme for the same penetration level, around 15\%, to make combination of storage with PV more attractive than simply increasing PV capacity has been profoundly shown in the arithmetic example.

The methodology and calculations of FIT for using 100\% RES to meet desalination loads has been shown for one case study. The results show that the development of FIT for storage is justified from several points of views (fuel savings, economic benefits, reduction of $\mathrm{CO}_{2}$ emissions, higher RES penetration and more effective RES utilisation).

Strong support and political will on local, national and international level to apply financial support mechanisms for energy storage systems and thus increase RES penetration is crucial for further development and application of energy storage technologies. All results presented correspond to a preliminary investigation of FIT for energy storage with some representative application and extended discussion. They do not represent an integrated framework to be considered but just one of the possible solutions. Another approach for financing energy storage is through the payment of grid management services. In this case, real costs and benefits of storage are usually hidden and not adequately remunerated. As EU plans to significantly increase RES share in electricity supply of some regions, additional storage capacity is required. Well structured and transparent feed-in tariffs have been proven as an effective mechanism and if used for energy storage they can ensure construction of the necessary new storage capacities within a reasonable time.

\section{Acknowledgements}

The authors would like to thank the European Commission for supporting Intelligent Energy Europe project STORIES (Addressing barriers to STORage technologies for increasing the penetration of Intermittent Energy Sources), Ministry of Science, Education and Sport of Republic of Croatia which is supporting the project Smart Energy Storage for Sustainable Development of Energy Systems and Portuguese Ministry of Economy and Innovation for financing
PRIME Programme which is supporting project EDEN_endogenous new energies (EDEN) that resulted in this work.

\section{References}

Agustin, Jose L.B., Lopez, Rodolfo D., 2008. Hourly energy management for gridconnected wind-hydrogen systems. International Journal for Hydrogen Energy 33 (22), 6401-6413.

Akash, Bilal A., AI-Jayyousi, Odeh R., Mohsen, Mousa S., 1997. Multi-criteria analysis of non-conventional energy technologies for water desalination in Jordan. Desalination 114, 1-12.

Barton, J.P., Infield, D., 2004. Energy storage and its use with intermittent renewable energy. IEEE Transactions on Energy Conversion 19, 2.

Bueno, C., Carta, J.A., 2006. Wind powered pumped hydro storage systems a means of increasing the penetration of renewable energy in the Canary Islands. Renewable and Sustainable Energy Reviews 10, 312-340.

Calero, R., Carta, J.A., 2004. Action plan for wind energy development in the Canary Islands. Energy Policy 32, 1185-1197.

Carvalho, Maria da Graça, Bonifacio, Matteo, Dechamps, Pierre, 2009. Building a low carbon society. In: Proceedings of the Fifth Dubrovnik Conference on Sustainable Development of Energy Water and Environment Systems. Invited Lecture on the 2 October 2009

Caralis, G., Zervos, A., 2006. Prospects of wind and pumped storage systems integration in Greek islands. Presented at the EWEA 2006, 27 February-2 March 2006.

Caralis, G., Rados, K., Zervos, A., 2010. On the market of wind with hydro-pumped storage systems in autonomous Greek islands. Renewable and Sustainable Energy Reviews 14, 2221-2226.

Connolly, D., et al., 2010. A review of computer tools for analysing the integration of renewable energy into various energy systems. Applied Energy 87 (4) 1059-1082.

Couture, T., Gagnon, Y., 2010. An analysis of feed-in tariff remuneration models: implications for renewable energy investment. Energy Policy 38, 955-965.

Danchev, Svetoslav, Maniatis, George, Tsakanikas, Aggelos, 2010. Returns on investment in electricity producing photovoltaic systems under de-escalating feed-in tariffs: the case of Greece. Renewable and Sustainable Energy Reviews $14,500-505$.

Deane, J.P., O'Gallachoir, B.P., McKeogh, E.J., 2010. Techno-economic review of existing and new pumped hydro energy storage plant. Renewable and Sustainable Energy Reviews 14, 1293-1302.

Duić, N., Lerer, M., Carvalho, M.G., 2003. Increasing the supply of renewable energy sources in island energy systems. International Journal of Sustainable Energy 23 (4), 177-186.

Duić, N., Carvalho, M.G., 2004. Increasing renewable energy sources in island energy supply: case study Porto Santo. Renewable and Sustainable Energy Reviews 8 (4), 383-399.

Duić, N., Krajačić, G., Carvalho, M.G., 2008. Renewislands methodology for sustainable energy and resource planning for islands. Renewable and Sustainable Energy Reviews 12 (4), 1032-1062.

European Commission, 2005. The support of electricity from renewable energy sources. SEC (2005) 1571, European Commission.

European Commission, 2008. Proposal for a Directive of the European Parliament and of the Council on the promotion of the use of energy from renewable sources; $\operatorname{COM}(2008) 19$ final; Brussels, 23.1.2008.

Estanqueiro, Ana, Castro, Rui, Flores, Pedro, Ricardo, João, Pinto, Medeiros, Rodrigues, Reis, Lopes, J.P., 2008. How to prepare a power system for $15 \%$ wind energy penetration: the Portuguese case study. Wind Energy 11, 75-84.

Garcia, J.L., Menendez, E., 2006. Spanish renewable energy: successes and untapped potential. In: Mallon, K. (Ed.), Renewable Energy Policy and Politics: A Guide for Decision Making. Earthscan, London, pp. 215-227.

Golden Valley Electric Association (GVEA), 2010. Fairbank's Battery Energy Storage System (BESS). Retrieved August 26, 2010 〈http://www.gvea.com/about/bess/〉.

Giebel, G, Brownsword, R, Kariniotakis, G., 2003. The State-of-the-Art in Short-term Prediction of Wind Power: A Literature Overview. Available on $\langle$ http://anemos. cma.fr/download/ANEMOS_D1.1_StateOfTheArt_v1.1.pdf $\rangle(27 / 11 / 08)$

Gonzalez, P.d.R., 2008. Ten years of renewable electricity policies in Spain: an analysis of successive feed-in tariff reforms. Energy Policy 36, 2917-2929.

Gonzalez, P.d.R., Gual, Miguel A., 2007. An integrated assessment of the feed-in tariff system in Spain. Energy Policy 35, 994-1012.

Haas, R., et al., 2004. How to promote renewable energy systems successfully and effectively. Energy Policy 32 (6), 833-839.

Hatziargyriou, N.D., Tsikalakis, A., Androutsos, A., 2006. Status of distributed generation in the Greek Islands, In: Proceedings of the 2006 IEEE PES General Meeting, Montreal, Canada.

Hellenic Republic; Ministry of Development, 2006. Law 3468/2006-Generation of Electricity using Renewable Energy Sources and High-Efficiency Cogeneration of Electricity and Heat and Miscellaneous Provisions (Official Gazette A' 129/ 27.06.2006), Athens, October 2006. Law, Renewable Energy Sources and Energy Saving Directorate, Directorate General For Energy, Athens.

Huber, C., et al., 2004. Green-X. Deriving optimal promotion strategies for increasing the share of RES-E in a dynamic European electricity market. Final Report of the EU-Funded Project GREEN-X, Vienna University of Technology, Austria.

Hvelplund, Frede, 2006. Renewable energy and the need for local energy markets. Energy 31, 2293-2302. 
Kaldellis, J.K., Kondili, E.M., 2007. The water shortage problem in the Aegean archipelago islands: cost-effective desalination prospects. Desalination 216, 123-138.

Kaldellis, J.K., Zafirakis, D., Kavadias, K., 2009. Techno-economic comparison of energy storage systems for island autonomous electrical networks. Renewable and Sustainable Energy Reviews 13 (2), 378-392.

Kapsali, M., Kaldellis, J.K., 2010. Combining hydro and variable wind power generation by means of pumped-storage under economically viable terms. Applied Energy 87, 3475-3485.

Karagiannis, I.C. Soldatos, P.G., 2010. Estimation of critical $\mathrm{CO}_{2}$ values when planning the power source in water desalination: the case of the small Aegean islands. Energy Policy. doi:10.1016/j.enpol.2010.03.009.

Kavadias, K., 2009. Techno-economic comparison of energy storage systems for island autonomous electrical networks. Renewable and Sustainable Energy Reviews 13 (2), 378-392.

Kelsey, B.L., 2006. Estimating the Value of Distributed Energy Storage to California in Combination with Solar Photovoltaics, Market Investigation, Preliminary Analysis and Recommendations for Further Research. Electric Power Research Institute.

Korpas, Magnus, Greiner, Christopher J., 2008. Opportunities for hydrogen production in connection with wind power in weak grids. Renewable Energy 33, 1199-1208.

Krajačić, G., Duić, N., Carvalho, M.G., 2009. $\mathrm{H}_{2}$ RES, Energy planning tool for islan energy systems - the case of the Island of Mljet. International Journal of Hydrogen Energy 34 (16), 7015-7026.

Krajačić, G., Martins, R., Busuttil, A., Duić, N., Carvalho, M.G., 2008. Hydrogen as an energy vector in the islands' energy supply. International Journal of Hydrogen Energy 33 (4), 1091-1103.

Labed, Sifeddine, 2008. PV large scale rural electrification programs and the development of desert regions. In: Sustainable Energy Production and Consumption. NATO Science for Peace and Security Series C: Environmental Security. Springer-Verlag, pp. 281-292.

Lesser, J.A., Su, X., 2008. Design of an economically efficient feed-in tariff structure for renewable energy development. Energy Policy 36, 981-990.

Lipp, J., 2007. Lessons for effective renewable electricity policy from Denmark, Germany and the United Kingdom. Energy Policy 35, 5481-5495.

Lund, H., 2005. Large-scale integration of wind power into different energy systems. Energy 30 (13), 2402-2412.

Lund, H., Andersen, A.N., 2005. Optimal designs of small CHP plants in a market with fluctuating electricity prices. Energy Conversion and Management 46, 893-904.

Lund, H., Duic, N., Krajacic, G., Carvalho, M.G., 2007. Two energy system analysis models: a comparison of methodologies and results. Energy 32 (6), 948-954.

Lund, H., Kempton, W., 2008. Integration of renewable energy into the transport and electricity sectors through V2G. Energy Policy 36 (9), 3578-3587.

Lüthi, S., 2010. Effective deployment of photovoltaics in the Mediterranean countries: balancing policy risk and return. Solar Energy 84 (6), 1059-1071.

Madeira Reversible-Hydro System, presentation by EEM-Empresa de Electricidade da Madeira S.A., at the "Sustainable Islands"-Energy Storage Solutions for Islands Conference, Estoril, Portugal, 25-26 March 2010. Available at <http:// www.storiesproject.eu $>$.

Meyer, Niels I., 2003. European schemes for promoting renewables in liberalised markets. Energy Policy 31, 665-676.

Oikonomou, E.K., et al., 2009. Renewable energy sources (RES) projects and their barriers on a regional scale: the case study of wind parks in the Dodecanese islands, Greece. Energy Policy 37, 4874-4883.

Papadopoulos, Michael, Boulaxis, Nikos, 2008. Operating policies for hybrid windhydro power stations in island. In: Proceedings of the European Wind Energy Conference \& Exhibition.

Papathanassiou, Stavros, Elen i Karamanou, Stefanos Papaefthymiou, Michael Papadopoulos, Boulaxis, Nikos, 2008. Operating policies for hybrid wind-hydro power stations in island. In: Proceedings of the European Wind Energy Conference \& Exhibition.

Parissis, O., et al., 2009a. STORIES project. Cost-Benefit Analysis. Retrieved April 23, $2010\langle$ www.storiesproject.eu〉.

Parissis, O.-S., Zoulias, E., Stamatakis, E., Sioulas, K., Alves, L., Martins, R., Tsikalakis, A., Caralis, G., 2009b. Integration of wind and hydrogen technologies in the power system of Corvo Island, Azores: a cost-benefit analysis. In: Proceedings of the HYSYDAYS-Third World Congress of Young Scientists on Hydrogen Energy Systems, 7-9 October, 2009 Turin, Italy.

Psychogiopoulos, M., Tsikalakis, A.G., Hatziargyriou, N.D., 2008. Short-term scheduling of reserve-osmosis desalination loads in hybrid systems. In: Proceeding of the Fourth European PV-Hybrid and Mini-Grid Conference, Glyfada, Greece, May 29/30, 2008, pp. 344-349.

Public Power Corporation (PPC), 2010. 〈www.ppc.gr〉.

Ragwitz, M., Hed, A., Resch, G., Haas, R., Faber, T., Huber, C., Morthorst, P.E., Jensen, S., Coenraads, R., Voogt, M., Reece, G., Konstantinaviciute, I., Heyder, B., 2007. Assessment and optimisation of renewable energy support schemes in the European electricity market. Final Report of the project OPTRES, Supported by the European Commission, Brussels.

Ragwitz, M., et al., 2009. Assessing the advantages and drawbacks of government trading of guarantees of origin for renewable electricity in Europe. Energy Policy 37, 300-307.

Rathmann, M., 2007. Do support systems for RES-E reduce EU-ETS-driven electricity prices? Energy Policy 35 (1), 342-349.

Rau, N.S., Taylor, B., 1998. A central inventory of storage and other technologies to defer distribution upgrades-optimization and economics. IEEE Transactions on Power Delivery 13 (1), 194-200.

Saenz de Miera, Gonzalo, Gonzalez, Pablo d.R., Vizcaino, Ignacio, 2008. Analysing the impact of renewable electricity support schemes on power prices: the case of wind electricity in Spain. Energy Policy 34 (9), 3345-3359.

Sambrailo, Dubravko, Ivić, Jure, 2000. First land-based plant for RO desalination in Croatia. Desalination 132, 329-335.

Sambrailo, Dubravko, Ivić, Jure, Krstulović., Ante, 2005. Economic evaluation of the first desalination plant in Croatia. Desalination 179 (1-3), 339-344.

Segurado, Raquel, Krajačić, Goran, Duić, Neven, Alves, Luís, 2011. Increasing the penetration of renewable energy resources in S. Vicente, Cape Verde. Applied Energy 88 (12), 466-472.

Solano-Peralta, M., et al., 2009. "Tropicalisation” of feed-in tariffs: a custom-made support scheme for hybrid PV/diesel systems in isolated regions. Renewable and Sustainable Energy Reviews 13, 2279-2294.

Suarez, S., et al., 2009. STORIES project. Barriers assessment and recommendations to overcome them. Retrieved April 23, $2010\langle$ www.storiesproject.eu 〉.

Swaminathan, S., Sen, R.K., 1998. Review of Power Quality Applications of Energy Storage Systems. Sandia National Laboratories Retrieved July 27, $2010<$ http:// www.prod.sandia.gov/cgi-bin/techlib/access-control.pl/1998/981513.pdf $\rangle$.

Tsikalakis, A., Hatziargyriou, N., Papadogiannis, K., Gigantidou, A., Stefanakis, J., Thalassinakis, E., (2003). Financial contribution of wind power on the island system of Crete. In: Proceedings of the RES for Islands Conference, Crete, pp. 21-31.

Tsikalakis, A., Tassiou, I., Hatziargyriou, N., 2004. Impact of energy storage in the secure and economic operation of small islands. In: Proceedings of the MedPower04, Lemessos, November 2004, MED04/CH33.

Tsikalakis, Antonis G., Hatziargyriou, Nikos D., Katsigiannis, Yiannis A., Pavlos, S.Georgilakis, 2009a. Impact of wind power forecasting error bias on the economic operation of autonomous power systems. Journal of Wind Energy 12 (4), 315-331.

Tsikalakis, Antonios G., Hatziargyriou, Nikos D., Caralis, George, Zervos, Arthouros, Zoulias, Emmanouel, Stamatakis, Emmanouel, Tsamalis, George, Parissis, Olga, Garcia, Salvador S., Alamo, Daniel Henríquez, 2009b. Market applications for energy storage methods and RES. STORIES project 〈www.storiesproject.eu $\rangle$.

Tsikalakis, Antonios G., Hatziargyriou, Nikos D., Caralis, George, Zervos, Arthouros, Zoulias, Emmanouel, Stamatakis, Emmanouel, Tsamalis, George, Parissis, Olga, Garcia, Salvador Suarez, Alamo, Daniel Henríquez, 2009c. Impact of different applications of Storage Systems in island power systems. In: Proceedings of the DISTRES Conference (Conference on the promotion of Distributed Renewable Energy Sources in the Mediterranean Region), Nicosia, Cyprus, 11-12 December 2009, Paper No. 131.

The European Parliament and the Council of the European Union, 2009. DIRECTIVE $2009 / 28 / E C$ on the promotion of the use of energy from renewable sources and amending and subsequently repealing Directives 2001/77/EC and 2003/30/EC. Official Journal of the European Union.

Wals, A.F., Hendriks, R.H., 2004. Economics of Energy Storage-An Analysis of the Administrative Consequences of Electricity Storage. Retrieved July 25, 2010 〈www.ecn.nl/docs/library/report/2004/c04006.pdf 〉.

Yau, T., Walker, L., Graham, H.L., Gupta, A., Raithel, R., 1981. Effect of battery storage devices on power system dispatch. Journal of the IEEE Transactions on Power Apparatus and Systems PAS-100 (1), 375-383.

Zoulias, E.I., Lymberopoulos, N., 2007. Techno-economic analysis of the integration of hydrogen energy technologies in renewable energy-based stand-alone power systems. Renewable Energy Journal 32 (4), 680-696. 